Cite as:

C. Maraveas, Local buckling of steel members under fire conditions: A review, Fire Technology (2018). https://doi.org/10.1007/s10694-018-0768-1

\title{
Local buckling of steel members under fire conditions: A review
}

\section{Chrysanthos Maraveas*}

Fire Safety Unit, University of Liege, Liege, Belgium

*corresponding author e-mail: c.maraveas@maraveas.gr

\begin{abstract}
Local buckling is a failure mode commonly observed in thin-walled structural steel elements. Even though its effect on their behaviour at ambient temperature conditions is well documented and incorporated in current design codes, this is not the case when such elements are exposed to fire. This paper focuses on the occurrence of local buckling in steel members at elevated temperatures by conducting a thorough review of the literature. Experimental data (over 400 in total) gathered from 16 different sources are presented for both hot-formed as well as cold-formed elements made from different cross-sectional geometries (rolled or welded H-sections, box sections, channels etc). The effect of local buckling (and the various parameters that influence it) on the failure temperature is discussed based on the collected experimental evidence. Finally, the methods (numerical modelling and proposed analytical expressions) used by different authors to understand this phenomenon for steel members exposed to fire are discussed.
\end{abstract}

Key Words: Local buckling, Steel elements, Fire Tests, Elevated temperatures, Cold-formed members 


\section{Introduction}

Local buckling is a phenomenon that influences the behaviour of thin-walled structural steel elements in a major way and it can be the determining factor for their design in contemporary construction. Its occurrence prevents slender sections from attaining their full capacity, greatly diminishes their load bearing capability and should be completely avoided to ensure the safety and serviceability of steel structures. In analytical methods used for conventional room temperature design, local buckling is typically taken into account by reducing the crosssection to an effective one [1]. While this phenomenon has been investigated for ambient temperature conditions, its occurrence and effect for members heated to elevated temperatures is not well understood up to today and more insight is needed to prevent it. Furthermore, the complete absence of an organised database of test or simulation results on the topic is noteworthy. These reasons highlight the need for a thorough literature review of the effect of local buckling on steel structural elements exposed to fire, which is presented in this paper. After collecting experimental data and analysis results from various sources, discussions are made about the parameters that make it critical at elevated temperatures and practical conclusions for its prevention are drawn. Directions for future research work are also highlighted. A clear distinction is made between hot-rolled and cold-formed steel sections, because their response is expected to be different at elevated temperatures (as it is in ambient conditions).

\section{Failure types of steel members under elevated temperatures and scope of work}

Steel structural elements can exhibit different failure modes when exposed to fire, depending on the type of the member, the loading, the support and boundary conditions etc. As in ambient temperature, columns can fail by global buckling, compression or local buckling depending on their slenderness and the existence of lateral restraint. Beams, on the other hand, are typically subjected to bending and fail by lateral torsional buckling (no side 
supports are provided), plastification of the cross-section (non-slender cross-section) or local buckling (slender cross-section). In cold-formed sections, distortional buckling can also occur in addition to local and global buckling. The above failure modes are clearly understood and well documented in the literature, with the exception of local buckling. Its effect on the capacity of the element is still under investigation and cannot be easily quantified. For this reason, the authors selected to focus only on this phenomenon and examine it separately from the other failure types typically encountered when heating steel structural elements.

\section{Local buckling according to the current design codes}

Most current design codes take into account the local buckling of steel hot-rolled elements. EN1993-1-1 [1], for example, classifies steel sections into four categories based on various geometrical parameters that affect their slenderness (flange and web thickness and length, etc). At ambient temperature, for the most slender section category, the code proposes two methodologies for incorporating the adverse effect of local buckling in the resistance, by reducing either the cross-section (effective width method) or its yield strength (reduced stress method). At elevated temperatures, EN1993-1-2 [2] suggests calculating the local buckling resistance based on the effective width method in conjunction with the mechanical properties of steel at room temperature, with the exception of the yield strength for which the reduction due to elevated temperature must be taken into account. Otherwise, verification of the load bearing capacity in the fire situation can be completely omitted if the steel temperature does not exceed $350^{\circ} \mathrm{C}$. The reduced cross-sectional area, as proposed by the Eurocode, is obtained by multiplying it with the plate buckling reduction factor $\rho$, calculated according to the equations below:

For internal compression elements:

$\rho=1$ for $\lambda_{\rho} \leq 0.5+\sqrt{0.085-0.055 \psi}$ 
$\rho=\frac{\lambda_{\rho}-0.55(3+\psi)}{\lambda_{\rho}{ }^{2}} \leq 1$ for $\lambda_{\rho}>0.5+\sqrt{0.085-0.055 \psi}$

For outstand compression elements:

$\rho=1$ for $\lambda_{\rho} \leq 0.748$

$\rho=\frac{\lambda_{\rho}-0.188}{\lambda_{\rho}^{2}} \leq 1$ for $\lambda_{\rho}>0.748$

with $\lambda_{\rho}=\frac{b / t}{28.4 \varepsilon \sqrt{k_{\sigma}}}$

where $\mathrm{b}, \mathrm{t}$ are the width and thickness of the element, $\psi$ is the stress ratio in the element, $\mathrm{k}_{\sigma}$ is a buckling factor depending on the boundary conditions and the factor $\psi$, and $\varepsilon=\sqrt{235 / f_{y}}$, with $\mathrm{f}_{\mathrm{y}}$ being the yield stress of the material in $\mathrm{N} / \mathrm{mm}^{2}$.

The AISC [3] code also provides a methodology to account for the effect of local buckling in compression elements at room temperature. If the elevated temperature material properties (provided in Appendix 4 of this code) are combined with this methodology, it is possible to estimate the local buckling of steel columns subjected to fire. In their research work, Quiel and Garlock [4] followed this methodology to calculate the ultimate buckling strength of steel plates at elevated temperatures.

Regarding cold-formed steel members, the majority of the current design codes, such as EN1993-1-3 [5], the AISI Cold-formed Steel Design Manual [6], BS5950 (Part 5) [7] and the Australian standard AS/NZS 4600 [8] provide equations to account for local buckling of columns only at room temperature conditions. Most of these include reducing the crosssectional area by introducing an effective width based on various slenderness parameters. On the contrary, the Direct Strength Method (DSM) specified in the supplement of the North American Specification [9] uses the full cross-section of the column and calculates the 
resistance based on the lowest of the global, local and distortional buckling resistances. According to this code, the local buckling resistance is calculated from formulas involving the elastic axial buckling load (columns) or the elastic lateral torsional buckling moment (beams). Only BS 5950 Part 8 [10] and EN1993-1-2 [2] provide some insight for the design of cold-formed members against local buckling at elevated temperatures, by suggesting the application of the rules used for hot-rolled elements with some limitations.

\section{Local Buckling of hot-rolled and welded steel structural elements at elevated temperatures}

In an attempt to understand the phenomenon of local buckling of steel members subjected to fire, many researchers carried out experiments or conducted extensive numerical simulations accompanied, in many cases, with analytical models. This section focuses on presenting and discussing relevant experimental data as well as proposed analysis methods for structural elements made either from rolled or welded sections encountered in the literature.

\subsection{Experimental studies of welded columns}

A very interesting experimental work on this topic was conducted by Yang et al [11], who tested two series of welded column stubs with varying width-to-thickness ratios (for each specimen, the flange width to thickness ratio was equal to that of the web) under fire exposure. The programme included 12 welded box sections and $12 \mathrm{H}$-sections made from fire resisting steel (structural steel with improved mechanical properties at elevated temperatures) and concluded that local buckling in such columns can be prevented if the temperature does not exceed $600^{\circ} \mathrm{C}$ and the width-to-thickness ratio is less than $1.14 *\left(\mathrm{E} / \mathrm{f}_{\mathrm{y}}\right)^{1 / 2}$ or $0.41 *\left(\mathrm{E} / \mathrm{f}_{\mathrm{y}}\right)^{1 / 2}$ for stiffened and unstiffened elements respectively [11], where E is Young's elastic modulus and $\mathrm{f}_{\mathrm{y}}$ the yield stress at ambient temperature. The failed $\mathrm{H}$-stubs after completion of the tests are shown in Fig. 1 [11], with local buckling in the flanges being evident. 


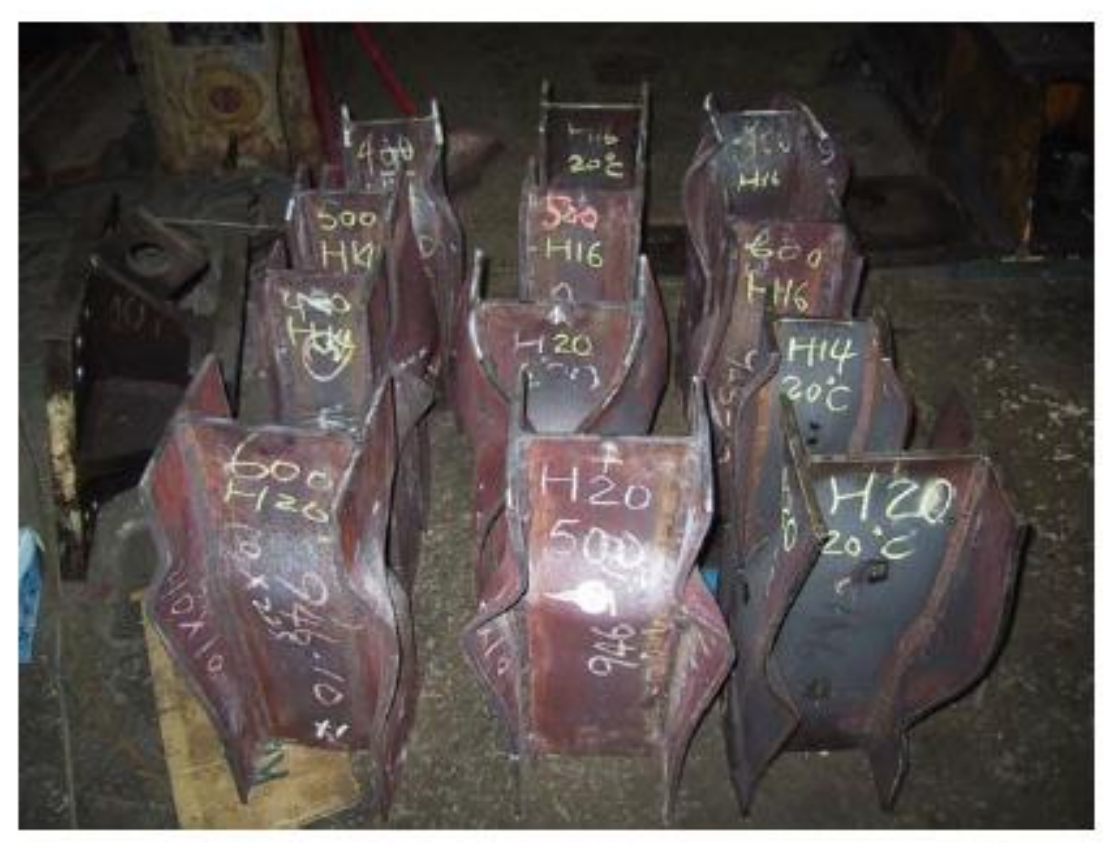

Figure 1: Failure of H-column specimens in the test programme carried out by Yang et al [11]

In similar research, Yang and Yang [12] tested five restrained welded steel box columns at room temperature and 10 similar columns exposed to fire (in steady state conditions, for a constant temperature of $500^{\circ} \mathrm{C}$ ) and measured their ultimate load. The authors also reported the failure mode of the specimens. In all occasions local buckling was observed, with the authors stating, however, that the impact of the width-to-thickness ratio on local buckling was less severe at elevated temperatures [12]. The effect of local buckling on the strength of welded H-shaped columns subjected to fire was also investigated by Wang et al [13], who tested 8 column specimens of two different steel grades at elevated temperatures and reported that the ultimate load was controlled by local buckling of the flanges and the web. Their test programme also involved testing of four column specimens with identical properties at ambient temperature. According to the authors [13], columns with a higher material strength were also found more susceptible to local buckling at elevated temperatures. This failure mode was not observed for the six columns with class 4 cross-sections (welded H-sections) tested at the University of Liège [14]. It was reported that for these columns, in which load 
eccentricity was introduced, the failure mode was essentially weak axis global buckling, combined with flange local buckling (typically at midheight). These tests are discussed with more details in $[15,16]$. Contrary to the experimental results of the other authors $[11,12,13]$, who tested short stocky columns, this failure type occurred, majorly, because of the high slenderness of these columns (in slender columns global buckling is critical and precipitates local buckling, when the latter occurs) and to some extent due to the eccentricity of the load (i.e. eccentricity will result in additional moment, which will adversely affect the flexuralbuckling resistance of the member). Authors [11, 12] agree with the anticipated conclusion that higher width-to-thickness ratios reduce the fire resistance of the sections. Researchers typically tested sections from materials of a yield strength around $400 \mathrm{kPa}$, with sections made from higher material strength showing a more rapid loss of load bearing capacity (possibly due to the loss of ductility of the material).

\subsection{Experimental studies of rolled columns}

Local buckling was also reported for column specimens -106 in total, mostly from Rectangular Hollow Sections (RHS) and Square Hollow Sections (SHS) sections- tested under fire conditions as referenced in the paper by Theofanous et al [17]. The majority of these tests were carried out in ETH, Zurich (detailed information about them is given in [18]), with the authors concluding that the reason for the observed local buckling failure was the small magnitude of the global geometric imperfections and the low slenderness values of the columns. Fig. 2 shows the local buckling failure of a SHS specimen and a $\mathrm{H}$-section specimen of the programme referenced by Theofanous et al. [17]. 

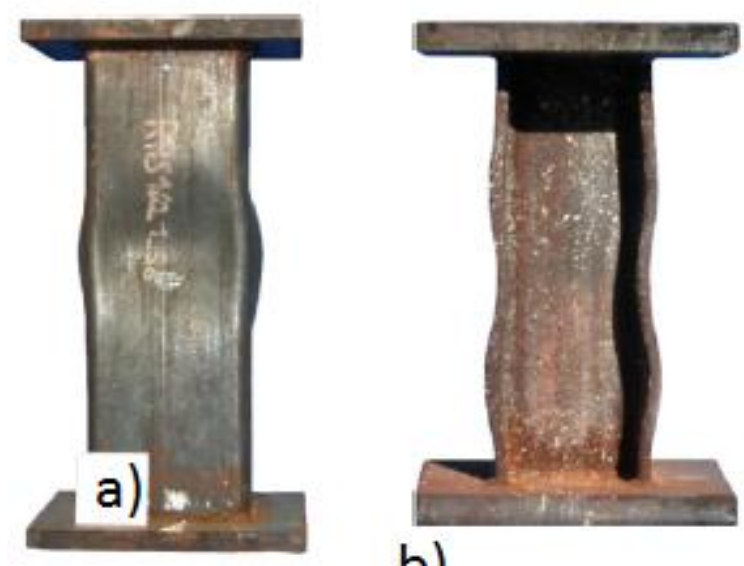

b)

Figure 2: Local buckling of a) SHS column stub and b) H-section column stub in the test programme referenced by Theofanous et al. [17]

In other experimental work [19], hot-rolled H-section column stubs were tested under fire exposure with the authors reporting failure due to local buckling at the flanges. More specifically, the programme included eight specimens tested under pure compression and 24 specimens tested under bending and compression. On the contrary, the two hot-rolled columns with H-sections tested in Liège [14] failed in global buckling with some evidence of local buckling similarly to the welded ones of the same test programme. It should be highlighted, however, that these were long slender columns and global buckling was the anticipated failure mode. Fig. 3 shows the failure of such a tested column. 


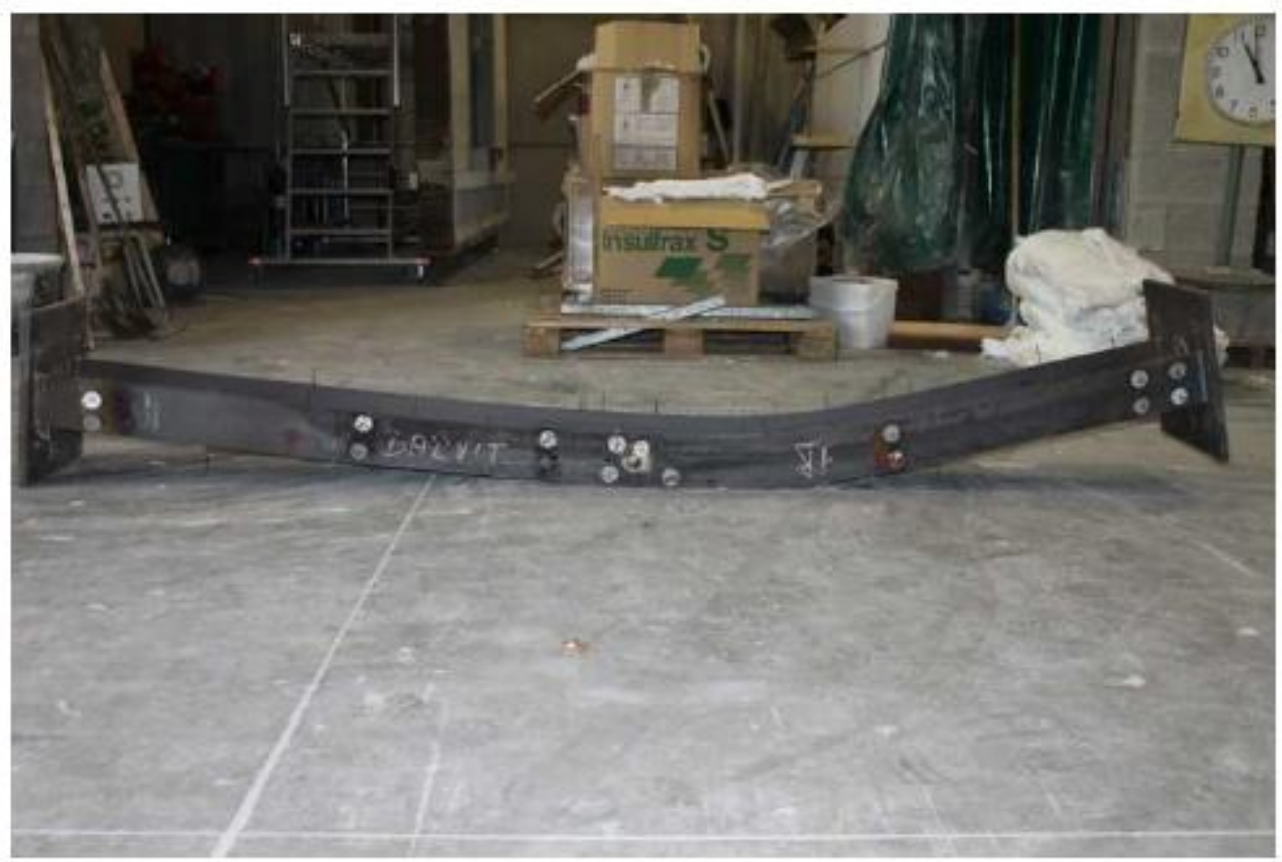

Figure 3: Global buckling of tested hot-rolled H-section after fire exposure [14]

\subsection{Experimental Studies of beams}

Contrary to columns, the experimental database of steel beams involving local buckling at elevated temperatures is far more limited. Prachar et al [20] tested seven simply supported welded beams made of slender sections (class 4 according to the Eurocodes) under steadystate fire conditions. Four of these beams were tested under pure bending (lateral restraint was provided) and exhibited intense local buckling at the upper flange at failure. For the remaining three (limited lateral restraint), the failure mode was predominantly lateral torsional buckling (LTB), with limited local buckling appearing only at the top flange around the midspan of the beam. The authors compared the experimental results with FEM simulations in ABAQUS and reported satisfactory agreement. A more thorough experimental programme [21] included the testing of eight welded beams (a set of four under bending with lateral restraints and another set of four under bending involving lateral torsional buckling-i.e. unrestrained beams) at elevated temperature conditions. The authors reported that, for the first set (the plate slenderness ratio for the flanges of these beams was either $b / t=10.5$ or 
$\mathrm{b} / \mathrm{t}=19$, where $\mathrm{b}$ is flange width and $\mathrm{t}$ its thickness), severe local buckling of the upper flange and the upper portion of the web was observed. Moreover, the effect of local buckling was more pronounced for the section with the greater flange width-to-thickness ratio [21]. The failure mode of the unrestrained set of beams was more complex, displaying lateral torsional buckling combined with upper flange local buckling at various locations [21]. The different phenomena in the two test sets are observed due to the presence of lateral supports (first set) that prevent the occurrence of lateral torsional buckling. In other research, Dharma and Tan [22] tested eight steel beams with varying cross-sections (three of which were welded) under elevated temperatures (steady-state heating). Intermediate supports at variable spacing were placed to provide different levels of lateral restraint for the tested beams. Rotational restraint was provided at the ends of the beams in order for a hogging moment to be developed (similar to the one of a continuous beam under bending). The authors reported local buckling failure of the flange and web near the midspan region for all the beams with closely spaced lateral supports. On the contrary, the three beams with limited lateral restraint exhibited LTB failure. Results from all these authors $[20,21,22]$ are in agreement in terms of the observed failure mode, with lateral restraint determining, in all cases, the appearance of local buckling or not.

\subsection{Numerical and Analytical Studies of steel elements}

Various attempts to investigate the effect of local buckling on the fire resistance of steel elements, via numerical methods and simulations, have been made in the last years. Couto et al [23], for example, simulated, via the Finite Element Method (FEM), a large number of short elements with slender cross-sections (i.e. susceptible to local buckling) under axial compression and bending and proposed a new methodology to calculate their resistance at elevated temperatures. This methodology follows the logic of the Eurocodes with new formulas proposed to calculate the effective cross-section which accounts for local buckling. 
The effect of local web buckling in steel cross-sections subjected to axial force and bending was investigated by Heidarpour and Bradford [24], who applied the Spline Finite Strip (SFS) method to determine the elastic local buckling coefficients and, consequently, the slenderness limits for steel webs at elevated temperatures. An analytical model to evaluate the local buckling of H-shaped steel columns exposed to fire was proposed by Ragheb [25], who then used this model to conduct a parametric study investigating local flange buckling and web buckling at elevated temperatures and define the critical buckling load. Furthermore, the stability of wide flange hot-rolled columns in terms of global and local buckling was investigated via the FEM by Seif and McAllister [26], who conducted a relevant parametric study including material nonlinearities and geometric imperfections. An analytical expression to estimate local buckling of high strength steel columns (for both H-shaped and tubular sections) exposed to fire was proposed and compared with FEM and experimental results in other work [27]. Other simulation models for determining the fire resistance of steel structural elements, while taking into account the effect of local buckling, were proposed and validated against finite element models or experimental results ([28], [29]). Contrary to the majority of researchers, who implemented shell finite elements in their analysis, Franssen, Cowez and Gernay [29] proposed an effective law to be used in beam finite elements as a simple way of taking into account local instabilities (and consequently local buckling) that may occur in slender sections when exposed to fire. Additionally, the experimental work of Wang et al [13] referring to short columns was simulated via the FEM with satisfactory accuracy. Other authors only used appropriate finite element modelling to incorporate local buckling of hot-rolled steel columns [30] or H-shaped steel members [31] at elevated temperatures. A new analytical method for the design of steel members against local buckling was proposed and validated against FEM simulations by Couto et al [32]. 
Regarding the effect of local buckling on the stability of beams under fire exposure, Naser and Kodur [33] created a three-dimensional nonlinear finite element model of a composite steel beam (hot-rolled steel beam with a concrete slab on top) in a commercial software (ANSYS). Their model took into account various parameters that affect the fire response of such a beam (e.g. geometrical imperfections, composite action etc). After a study that involved the variation of several parameters, they concluded that web local buckling can affect the stability of the beam and lead to premature shear failure. The authors also reported that, in their simulations, local buckling appeared at lower temperatures for higher steel grades. In other research [21], 3D finite element models simulating eight fire experiments of welded beams were created using three different commercial programs (SAFIR, ANSYS and ABAQUS) for the purpose of achieving better accuracy in the simulations. A comparison of the results showed satisfactory agreement between experiments and numerical simulations (despite the use of different software, the obtained numerical results are similar), with the effect of local buckling being captured correctly (Fig. 4). Other data from beam tests were also compared with results from FEM analysis [20]. After a very thorough parametric study involving numerous finite element simulations of hot-rolled and welded beams under fire conditions, Couto et al [34] proposed an analytical expression to calculate the LTB resistance, which incorporated the effect of local buckling by introducing an effective section factor. 


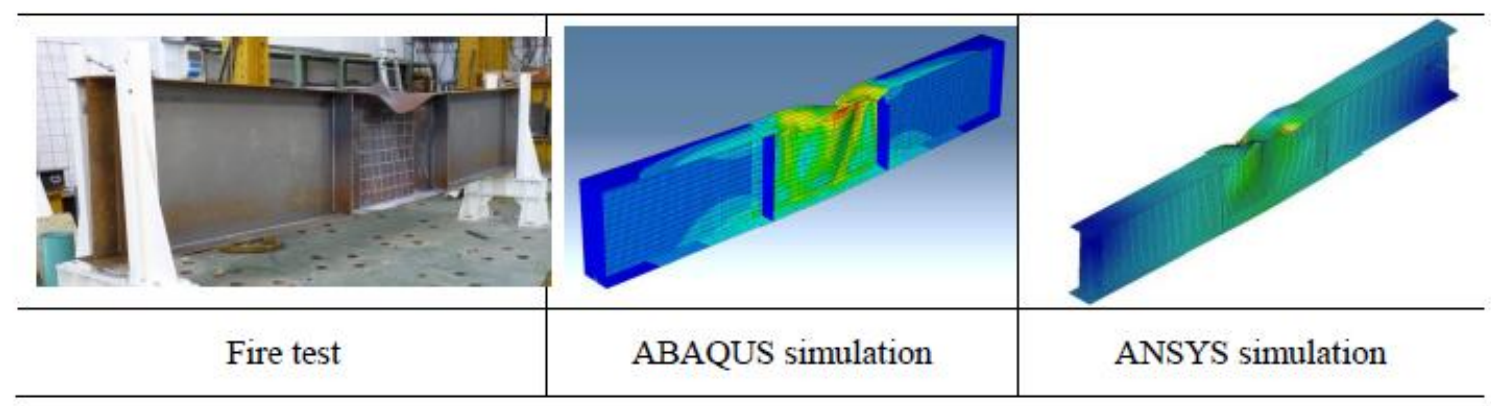

Figure 4: Comparison of the fire test failure mode with the FEM simulations for one of the tested beams in the FIDESC4 programme [21]

Furthermore, Dharma and Tan [35] created FEM models to simulate the behaviour of the beams tested in their research program [22] and reported good accuracy between experimental and numerical results. They also state that their models capture well the observed failure modes, including local buckling. Following that, the same authors [35] conducted parametric analyses to investigate the effect of various parameters on the rotational capacity of beams subjected to fire and reported that increasing web, flange and LTB slenderness reduces it. Based on these FEM studies, they also proposed a simple momentrotation relationship for steel beams at elevated temperatures.

Couto et al [36] investigated numerically the effect of local buckling on laterally restrained steel beam-columns (i.e. members subjected to axial force and moment concurrently) exposed to fire. After a thorough parametric study involving the FEM, they concluded that the current provisions of the Eurocode (EN1993-1-2 [2]) are not sufficient to describe the phenomenon for such elements and in certain cases overestimate their capacity. Additionally, numerical investigations of slender cross-sections (Class 4 according to the Eurocode) exposed to fire were conducted by other researchers [37]. Based on their results, these authors proposed new critical temperatures to prevent local buckling of such sections and suggested that these given in the Eurocode are conservative. Knobloch and Fontana [38] applied the effective width principle to propose a strain-based approach (which includes plastification 
effects, initial imperfections, material non-linearity, etc.) quantifying the effect of local buckling on the capacity of stiffened and unstiffened elements at elevated temperatures and validated their proposal via a large number of FEM simulations. Local buckling of thin steel plates at elevated temperature was also investigated by others [39], who proposed new equations for calculating the effective width of outstand (flanges) or internal elements (webs) based on results from extensive numerical simulations. In similar fashion, a new stress-based approach for calculating the buckling strength of plates under fire exposure was proposed by Quiel and Garlock [4].

Based on the numerical analyses encountered in the literature, several parameters should be taken into account by researchers or designers when modelling steel elements that exhibit local buckling under elevated temperature effects. Selection of the appropriate finite element type and mesh is crucial, with 4-noded shell elements that can attain large strains (suitable for describing nonlinear behaviour) being successfully used in the literature to model the steel structural elements. Moreover, authors implemented a dense mesh capture local buckling, which is highly recommended for similar future work. Refining the mesh produces more accurate results according to the work of Agarwal, Varma and Cedeno [30]. Modelling should include the appropriate variation of the material properties (such as the yield stress, elastic modulus etc.) with temperature, based on experimental results or other certified methods. Initial geometric imperfections should also be taken into account in future modelling attempts of such elements, as they affect the evolution of local buckling at elevated temperatures according to simulation results. Typical values used range from $\mathrm{L} / 1000$ to $\mathrm{L} / 1500$, where $\mathrm{L}$ is the length of the member. Contrary to the numerical findings of two authors $[21,26]$, the incorporation of residual stresses in such models was reported to influence simulation results, especially for lower temperatures $[27,30,34]$, and is recommended for similar future work. 


\subsection{Discussion of the literature}

The data (experimental and numerical) gathered from the literature related to hot-formed sections are presented in Table 1 . Information (applied loading, boundary conditions etc.) related to the relevant fire tests encountered in the literature is summarized in Table 2. It can be observed that most tests refer to column elements (188 experiments from 7 sources) rather than beams ( 23 experiments from three sources). Both welded (59 tests from 7 sources) as well as rolled sections (140 tests from 3 sources) have been tested. Experimental work pertaining to beams is more limited, with a total of 23 tests (welded or hot-rolled I-beams only) from three sources being reported. In spite of the fact that both box and H-shaped columns were investigated experimentally, authors simulated mostly elements of the latter cross-section type. Moreover, the FEM was selected by most authors to model the effect of local buckling for hot-formed steel elements exposed to fire, with only four sources, however, presenting analytical expressions. Comparison of the FEM simulations with tests showed good agreement according to the authors.

Table 1: Experimental data and numerical simulations of hot-formed steel members exposed to fire

\begin{tabular}{|c|c|c|c|c|c|}
\hline Source & $\begin{array}{c}\text { Member } \\
\text { Type }\end{array}$ & Cross-section & Experiments & $\begin{array}{c}\text { No. of } \\
\text { specimens } \\
\text { with Local } \\
\text { Buckling } \\
\text { Failure }\end{array}$ & $\begin{array}{c}\text { Analysis } \\
\text { Method }\end{array}$ \\
\hline$[11]$ & Column & Welded H & 12 & 12 & - \\
\hline$[11]$ & Column & Welded Box & 12 & 12 & - \\
\hline$[12]$ & Column & Welded Box & 10 & 10 & FEM \\
\hline$[13]$ & Column & Welded H & 8 & 8 & FEM \\
\hline$[14]$ & Column & Welded H & 6 & 6 & - \\
\hline$[17]$ & Column & $\begin{array}{c}\text { Rolled } \\
\text { SHS,RHS,H }\end{array}$ & 106 & 106 & FEM \\
\hline$[19]$ & Column & Hot-rolled H & 32 & 32 & FEM \\
\hline$[14]$ & Column & Hot-rolled H & 2 & 2 & 4 \\
\hline$[20]$ & Beam & Welded H & 7 & & \\
\hline
\end{tabular}




\begin{tabular}{|c|c|c|c|c|c|}
\hline [21] & Beam & Welded $\mathrm{H}$ & 8 & 8 & FEM \\
\hline [23] & $\begin{array}{c}\text { Not } \\
\text { Specified }\end{array}$ & Welded H & - & - & FEM+Equations \\
\hline [24] & $\begin{array}{c}\text { Not } \\
\text { Specified }\end{array}$ & $\mathrm{H}$ & - & - & SFS \\
\hline [25] & Column & $\mathrm{H}$ & - & - & Equations \\
\hline [26] & Column & Hot-rolled H & - & - & FEM \\
\hline [27] & Column & Welded H, Box & - & - & FEM \\
\hline$[28],[29]$ & $\begin{array}{c}\text { Not } \\
\text { Specified }\end{array}$ & $\mathrm{H}$ & - & - & FEM \\
\hline [30] & Column & Hot-rolled H & - & - & FEM \\
\hline$[31]$ & $\begin{array}{c}\text { Not } \\
\text { Specified }\end{array}$ & $\mathrm{H}$ & - & - & FEM \\
\hline [32] & $\begin{array}{c}\text { Not } \\
\text { Specified } \\
\end{array}$ & $\mathrm{H}$ & - & - & FEM+Equations \\
\hline [33] & Beam & Hot-rolled H & - & - & FEM \\
\hline [34] & Beam & $\begin{array}{l}\text { Hot-rolled, } \\
\text { welded H }\end{array}$ & - & - & FEM+Equations \\
\hline$[35],[22]$ & Beam & $\begin{array}{l}\text { Hot-rolled, } \\
\text { welded H }\end{array}$ & 8 & 6 & FEM+Equations \\
\hline [36] & $\begin{array}{l}\text { Beam- } \\
\text { Column }\end{array}$ & $\mathrm{H}$ & - & - & FEM \\
\hline [37] & $\begin{array}{l}\text { Cross- } \\
\text { section }\end{array}$ & - & - & - & FEM \\
\hline [38] & $\begin{array}{l}\text { Cross- } \\
\text { section }\end{array}$ & - & - & - & FEM+Equations \\
\hline [39] & Plates & - & - & - & FEM+Equations \\
\hline [4] & Plates & - & - & - & FEM+Equations \\
\hline
\end{tabular}


Table 2: Information regarding the fire tests of hot-rolled/welded steel members collected from the literature

\begin{tabular}{|c|c|c|c|c|c|}
\hline Source & $\begin{array}{l}\text { Member } \\
\text { Type }\end{array}$ & Cross-section & $\begin{array}{l}\text { Heating } \\
\text { method }\end{array}$ & $\begin{array}{l}\text { Loading } \\
\text { Condition }\end{array}$ & $\begin{array}{c}\text { Boundary } \\
\text { Conditions }\end{array}$ \\
\hline [11] & Column & Welded H or Box & Steady-state & Axial Load & $\begin{array}{l}\text { No axial restraint } \\
\text { at the ends }\end{array}$ \\
\hline [12] & Column & Welded Box & Steady-state & Axial Load & $\begin{array}{c}\text { Axial \& rotational } \\
\text { restraint at the } \\
\text { ends }\end{array}$ \\
\hline [13] & Column & Welded H & Steady-state & Axial Load & $\begin{array}{l}\text { Axial \& rotational } \\
\text { restraint at the } \\
\text { ends }\end{array}$ \\
\hline [14] & Column & $\begin{array}{l}\text { Welded or Hot- } \\
\text { rolled H }\end{array}$ & Transient & Axial Load & $\begin{array}{l}\text { Pinned supports } \\
\text { the ends }\end{array}$ \\
\hline [17] & Column & Rolled SHS,RHS,H & Steady-state & Axial Load & $\begin{array}{c}\text { Fixed supports at } \\
\text { the ends }\end{array}$ \\
\hline [19] & Column & Hot-rolled H & Steady-state & $\begin{array}{l}\text { Axial Load or } \\
\text { Axial Load } \\
\text { +Bending }\end{array}$ & Fixed Ends \\
\hline [20] & Beam & Welded H & Steady-state & $\begin{array}{l}\text { Bending under } \\
\text { two point loads }\end{array}$ & $\begin{array}{l}\text { Simply supported } \\
\text { ends, lateral } \\
\text { restraints at load } \\
\text { points }\end{array}$ \\
\hline [21] & Beam & Welded H & Steady-state & Bending & $\begin{array}{l}\text { Simply supported } \\
\text { beams, } 4 \text { beams } \\
\text { with restraints } \\
\text { against LTB }\end{array}$ \\
\hline [22] & Beam & $\begin{array}{c}\text { Hot-rolled, welded } \\
\text { H }\end{array}$ & Steady-state & $\begin{array}{l}\text { Bending under } \\
\text { midpoint load }\end{array}$ & $\begin{array}{l}\text { No axial restraint, } \\
\text { rotational restraint } \\
\text { at the ends, lateral } \\
\text { support at the } \\
\text { middle and along } \\
\text { the length }\end{array}$ \\
\hline
\end{tabular}

The two figures below show plots of the load ratio versus the failure temperature for some of the tested columns with box-sections (Fig. 5) or H-sections (Fig. 6), as reported in the literature. The plotted data refer to specimens that failed explicitly by local buckling (i.e. their failure did not involve global buckling; all plotted results refer to short and stocky columns), in order for the various factors that affect this phenomenon at elevated temperatures to be clearly identified. The load ratio is defined here as ratio of the measured load for which the column failed divided by the calculated compression resistance (including the effect of local 
buckling) of the cross-section at ambient conditions. In these figures, the plate slenderness ratio $b / t$ (where $b$ is the width of the web or the flange, depending on the location of the local buckling, and $\mathrm{t}$ is the thickness) is also marked. When referring to flanges, $\mathrm{b}$ is either the total width (stiffened elements -i.e. flanges of box sections) or half of the width (unstiffened elements - i.e flanges of $\mathrm{H}$ - sections) of the element. The failure type, i.e. local flange buckling (LFB) or local web buckling (LWB), is also indicated.

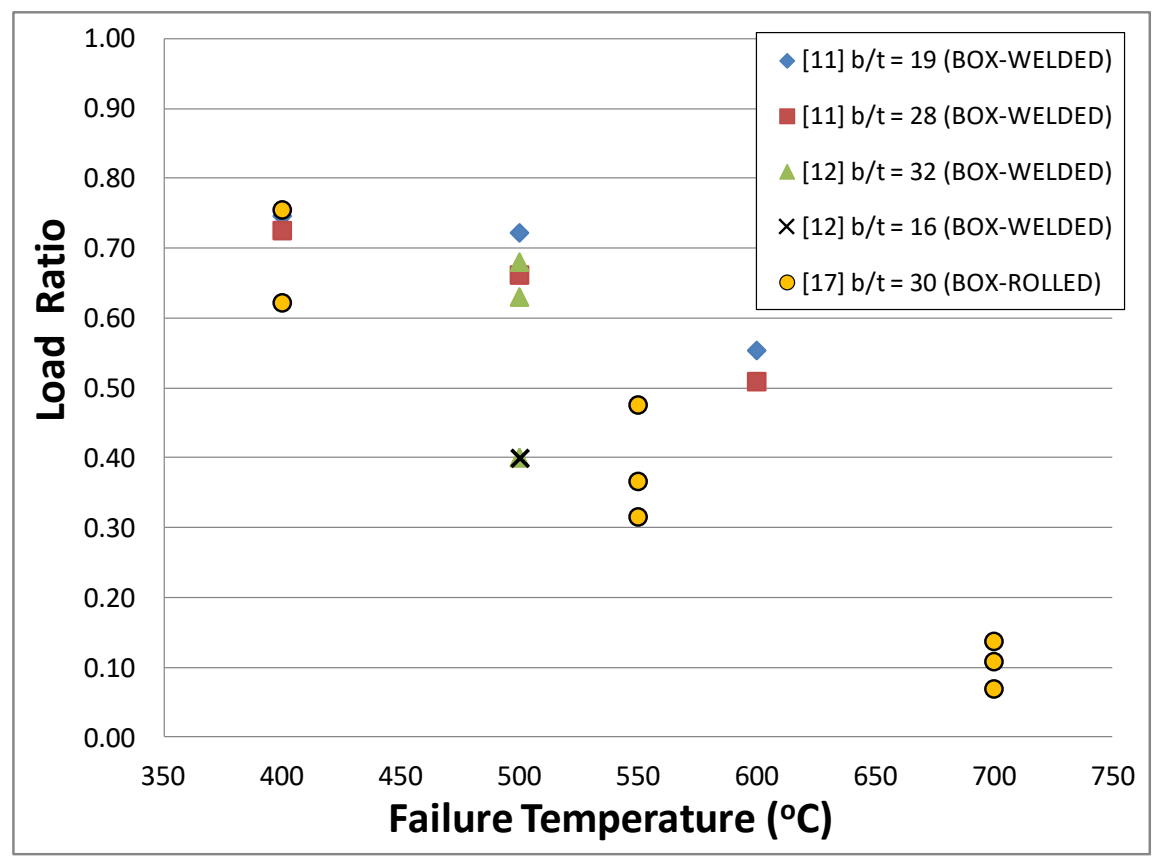

Figure 5: Plot of the load ratio versus the failure temperature for stocky box columns (welded or hot-rolled) experiencing local buckling under elevated temperatures (experimental data collected from the literature [11],[12],[17]) 


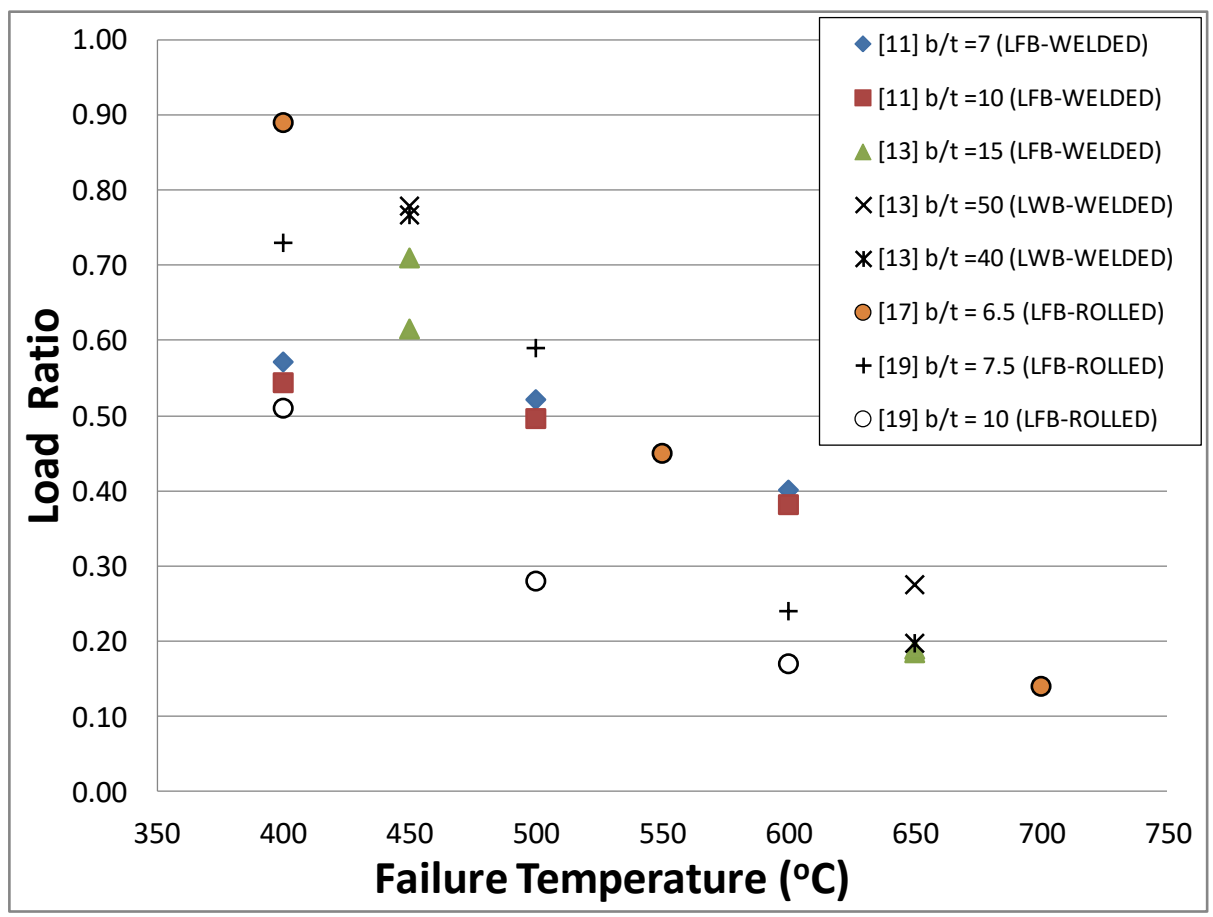

Figure 6: Plot of the load ratio versus the failure temperature for stocky columns with Hsections (welded or hot-rolled) experiencing local buckling under elevated temperatures (experimental data collected from the literature [11],[13],[17],[19])

As expected, temperature increase leads to failure at lower load ratios despite the noticeable scatter in the data. Both welded and hot-rolled columns follow a similar trend in their loss of strength due to local buckling, with load ratios as low as 0.1 being observed for temperatures around $700^{\circ} \mathrm{C}$. This reduction in strength occurs because of the significant deterioration of the properties of steel between $400^{\circ} \mathrm{C}$ and $700^{\circ} \mathrm{C}$. Remarkable is also the absence of data below $400^{\circ} \mathrm{C}$, with no failures being reported in the literature at lower temperatures. The variation of the $b / t$ ratios apparently affects the load ratio at failure, with higher $b / t$ ratios leading, in most cases, to lower failure temperatures for the same load ratio.

In order to better understand the effect of width-to-thickness ratio on local buckling at elevated temperatures, experimental data (for temperatures lower than $600^{\circ} \mathrm{C}$ ) from the above figures are tabulated in Table 3 and the $\mathrm{b} / \mathrm{t}$ ratio is compared with the values of $0.41 *\left(\mathrm{E} / \mathrm{f}_{\mathrm{y}}\right)^{1 / 2}$ or $1.14 *\left(E / f_{y}\right)^{1 / 2}$ for unstiffened or stiffened elements respectively (which were proposed by Yang et al [11] as threshold values for local buckling in their experimental work), where E is 
Young's modulus of elasticity and $\mathrm{f}_{\mathrm{y}}$ the yield stress at room temperature. It can be seen that the $b / t$ ratio is in the region of these threshold values (generally lower). It can therefore be stated that local buckling for stocky columns can be prevented for temperatures lower than $600^{\circ} \mathrm{C}$, provided that the $\mathrm{b} / \mathrm{t}$ ratio is less than $0.41 *\left(\mathrm{E} / \mathrm{f}_{\mathrm{y}}\right)^{1 / 2}$ (unstiffened elements) or $1.14 *\left(\mathrm{E} / \mathrm{f}_{\mathrm{y}}\right)^{1 / 2}$ (stiffened elements) and the load ratio is not greater than 0.55 .

Table 3: Tabulated experimental data for short/stocky columns collected from the literature

\begin{tabular}{|c|c|c|c|c|c|}
\hline Source & $\begin{array}{c}\text { Load } \\
\text { Ratio }\end{array}$ & $\begin{array}{c}\text { Failure } \\
\text { Temperature }\left({ }^{\circ} \mathrm{C}\right)\end{array}$ & $\mathrm{b} / \mathrm{t}$ & $\begin{array}{c}1.14 *\left(\mathrm{E} / \mathrm{f}_{\mathrm{y}}\right)^{1 / 2}[11] / \\
\text { Unstiffened elements }\end{array}$ & $\begin{array}{c}0.41^{*}\left(\mathrm{E} / \mathrm{f}_{\mathrm{y}}\right)^{1 / 2}[11] / \\
\text { Stiffened elements }\end{array}$ \\
\hline$[17]$ & 0.14 & 700 & 6.3 & - & 9.2 \\
\hline$[19]$ & 0.24 & 600 & 7.5 & - & 10.0 \\
\hline$[19]$ & 0.17 & 600 & 10.0 & - & 9.6 \\
\hline$[11]$ & 0.53 & 600 & 7.0 & - & 9.7 \\
\hline$[11]$ & 0.53 & 600 & 8.0 & - & 9.5 \\
\hline$[11]$ & 0.51 & 600 & 10.0 & - & 10.6 \\
\hline$[13]$ & 0.18 & 650 & 15.0 & - & - \\
\hline$[13]$ & 0.19 & 650 & 13.5 & - & - \\
\hline$[17]$ & 0.11 & 700 & 29.6 & 27.2 & - \\
\hline$[17]$ & 0.07 & 700 & 29.6 & 27.2 & - \\
\hline$[17]$ & 0.14 & 700 & 30.8 & 26.8 & - \\
\hline$[11]$ & 0.55 & 600 & 19.2 & 27.0 & - \\
\hline$[11]$ & 0.55 & 600 & 23.0 & 27.0 & 26.4 \\
\hline$[11]$ & 0.51 & 600 & 28.0 & & \\
\hline
\end{tabular}

Furthermore, the experimental failure temperatures for the specimens presented in Fig. 5 and Fig. 6 are compared with the critical temperatures given by Maia et al [37] for the prevention of local buckling of class 4 cross-sections (Table 4). It can be observed that for approximate load ratios (less than $15 \%$ variation), the proposed minimum temperatures exceed the measured ones typically by $50^{\circ} \mathrm{C}$ to $100^{\circ} \mathrm{C}(10 \%$ to $25 \%)$. In eight cases the values were identical. Only six measurements were lower than the suggested values, with the difference varying from $10 \%\left(50^{\circ} \mathrm{C}\right)$ to $20 \%\left(100^{\circ} \mathrm{C}\right)$. Therefore, depending on the applied load ratio, the proposed critical temperatures can be used as a safe side approximation to prevent local buckling of steel members subjected to fire. 
Table 4: Comparison of failure temperatures measured from experimental data with proposed failure temperatures for class 4 cross-sections according to Maia et al [37]

\begin{tabular}{|c|c|c|c|c|c|}
\hline Source & $\begin{array}{c}\text { Experimental } \\
\text { Load Ratio }\end{array}$ & $\begin{array}{c}\text { Experimental } \\
\text { Failure } \\
\text { Temperature }\left({ }^{\circ} \mathrm{C}\right)\end{array}$ & $\begin{array}{c}\text { Load } \\
\text { Ratio [37] }\end{array}$ & $\begin{array}{c}\text { Expected Failure } \\
\text { Temperature }\left({ }^{\circ} \mathrm{C}\right) \\
{[37]}\end{array}$ & $\begin{array}{c}\text { Difference in } \\
\text { Temperature } \\
(\%)\end{array}$ \\
\hline [17] & 0.62 & 400 & 0.65 & 400 & 0 \\
\hline [17] & 0.37 & 550 & 0.40 & 550 & 0 \\
\hline [17] & 0.32 & 550 & 0.30 & 600 & -8 \\
\hline [17] & 0.48 & 550 & 0.50 & 500 & 10 \\
\hline [11] & 0.75 & 400 & 0.65 & 400 & 0 \\
\hline [11] & 0.72 & 500 & 0.65 & 400 & 25 \\
\hline [11] & 0.55 & 600 & 0.50 & 500 & 20 \\
\hline [11] & 0.73 & 400 & 0.65 & 400 & 0 \\
\hline [11] & 0.66 & 500 & 0.65 & 400 & 25 \\
\hline [11] & 0.51 & 600 & 0.50 & 500 & 20 \\
\hline [12] & 0.40 & 500 & 0.40 & 550 & -9 \\
\hline [12] & 0.40 & 500 & 0.40 & 550 & -9 \\
\hline [12] & 0.68 & 500 & 0.65 & 400 & 25 \\
\hline [12] & 0.63 & 500 & 0.65 & 400 & 25 \\
\hline [12] & 0.40 & 500 & 0.40 & 550 & -9 \\
\hline [17] & 0.45 & 550 & 0.40 & 550 & 0 \\
\hline [19] & 0.73 & 400 & 0.65 & 400 & 0 \\
\hline [19] & 0.59 & 500 & 0.65 & 400 & 25 \\
\hline [19] & 0.24 & 600 & 0.30 & 600 & 0 \\
\hline [19] & 0.51 & 400 & 0.50 & 500 & -20 \\
\hline [19] & 0.28 & 500 & 0.30 & 600 & -17 \\
\hline [11] & 0.52 & 500 & 0.65 & 400 & 25 \\
\hline [11] & 0.40 & 600 & 0.50 & 500 & 20 \\
\hline [11] & 0.52 & 500 & 0.65 & 400 & 25 \\
\hline [11] & 0.40 & 600 & 0.50 & 500 & 20 \\
\hline [11] & 0.54 & 400 & 0.65 & 400 & 0 \\
\hline [11] & 0.50 & 500 & 0.65 & 400 & 25 \\
\hline [11] & 0.38 & 600 & 0.50 & 500 & 20 \\
\hline [13] & 0.62 & 450 & 0.65 & 400 & 13 \\
\hline [13] & 0.71 & 450 & 0.65 & 400 & 13 \\
\hline [13] & 0.28 & 650 & 0.30 & 600 & 8 \\
\hline [20] & 0.63 & 450 & 0.65 & 400 & 13 \\
\hline [20] & 0.24 & 650 & 0.30 & 600 & 8 \\
\hline [20] & 0.71 & 450 & 0.65 & 400 & 13 \\
\hline [20] & 0.28 & 650 & 0.30 & 600 & 8 \\
\hline [21] & 0.70 & 450 & 0.65 & 400 & 13 \\
\hline [21] & 0.25 & 650 & 0.30 & 600 & 8 \\
\hline [21] & 0.69 & 450 & 0.65 & 400 & 13 \\
\hline [21] & 0.29 & 650 & 0.30 & 600 & 8 \\
\hline [22] & 0.46 & 615 & 0.50 & 500 & 23 \\
\hline
\end{tabular}




\begin{tabular}{|l|l|l|l|l|l|}
\hline$[22]$ & 0.46 & 615 & 0.50 & 500 & 23 \\
\hline$[22]$ & 0.48 & 615 & 0.50 & 500 & 23 \\
\hline$[22]$ & 0.45 & 615 & 0.50 & 500 & 23 \\
\hline
\end{tabular}

A plot of the load ratio versus the failure temperature of welded or hot-rolled beams that exhibited local buckling failures after fire exposure is given in Fig.7. These data were collected from three sources ([20],[21],[22]) and correspond to specimens that failed explicitly by local buckling (i.e. LTB was prevented by lateral restraints). The experimental data fall within two distinct temperature regions, namely $400^{\circ} \mathrm{C}$ to $450^{\circ} \mathrm{C}$ and $600^{\circ} \mathrm{C}$ to $650^{\circ} \mathrm{C}$, with a complete absence of data between these values being noticed. Data for temperatures below $400^{\circ} \mathrm{C}$ are not reported in the literature either. The flange width-tothickness ratio b/t is also noted in Fig.7, because the authors reported local flange buckling as the predominant failure mode of the tested beams (local web buckling was less intense and occurred afterwards). Temperature rise results in an almost linear decrease of the load ratio for the tested beams, with temperatures as high as $650^{\circ} \mathrm{C}$ being reported when the load ratio is approximately 0.25 . Furthermore, sections for which the flange $b / t$ ratio was less or equal than 8 were able to sustain greater load ratios when heated in the same temperature region. More specifically, the load ratio increased from 0.65 to 0.95 (approximately $45 \%$ ) around the $400^{\circ} \mathrm{C}-450^{\circ} \mathrm{C}$ region and from 0.25 to 0.45 (approximately $80 \%$ ) around the $600^{\circ} \mathrm{C}-650^{\circ} \mathrm{C}$ region when $\mathrm{b} / \mathrm{t}$ was less than or equal to 8 for the beam flanges. 


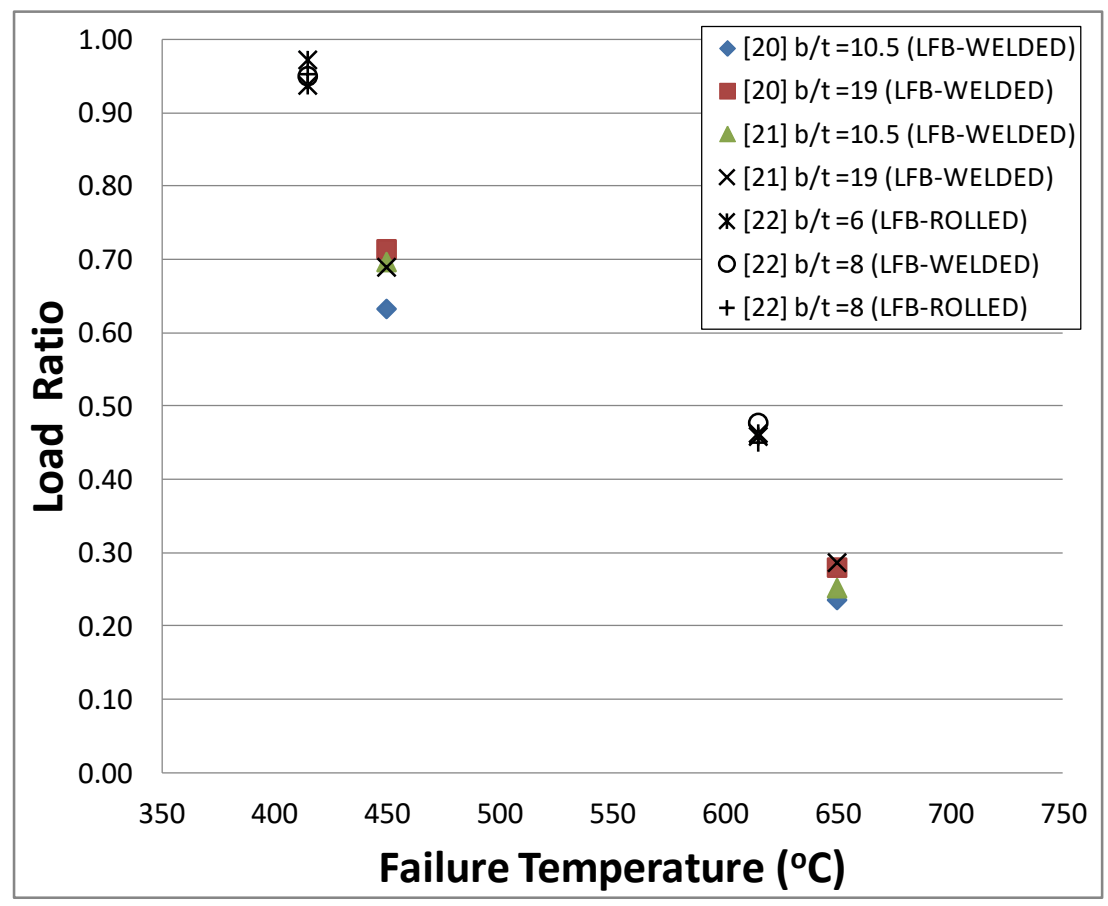

Figure 7: Plot of the load ratio versus the failure temperature for beams with H-sections (welded or hot-rolled) experiencing local buckling under elevated temperatures (experimental data collected from the literature [20],[21],[22])

Evaluating the analytical expressions for the local buckling of steel plates exposed to fire with respect to experimental data is also extremely useful and can certainly provide insight for future work. For this purpose, the ultimate load of the tested specimens (as collected from the literature) is compared with that calculated according to the expressions provided by Quiel and Garlock [4], at the reported experimental failure temperature. Table 5 provides the relevant information. It can be observed that the analytical model describes the experimental results with approximately a $25 \%$ difference (calculated results are more conservative in almost all cases) and can be used for a rough estimation of the failure load due to local buckling for heated steel members.

Table 5: Comparison of the ultimate load measured from experimental data with the calculated ultimate load for plates according to Quiel and Garlock [4]

\begin{tabular}{|c|c|c|c|c|}
\hline Source & $\begin{array}{c}\text { Experimental } \\
\text { Failure Load }(\mathrm{kN})\end{array}$ & $\begin{array}{c}\text { Calculated [4] } \\
\text { Failure Load }(\mathrm{kN})\end{array}$ & $\begin{array}{c}\text { Experimental } \\
\text { Failure }\end{array}$ & $\begin{array}{c}\text { Difference in } \\
\text { Load }(\%)\end{array}$ \\
\hline
\end{tabular}




\begin{tabular}{|c|c|c|c|c|}
\hline & & & Temperature $\left({ }^{\circ} \mathrm{C}\right)$ & \\
\hline [17] & 795 & 736 & 400 & 7.4 \\
\hline [17] & 468 & 472 & 550 & 0.9 \\
\hline [17] & 403 & 472 & 550 & 17.2 \\
\hline [17] & 138 & 139 & 700 & 0.9 \\
\hline [17] & 88 & 139 & 700 & 58.3 \\
\hline [17] & 408 & 300 & 400 & 26.5 \\
\hline [17] & 257 & 192 & 550 & 25.1 \\
\hline [17] & 74 & 57 & 700 & 23.3 \\
\hline [17] & 996 & 783 & 400 & 21.4 \\
\hline [17] & 511 & 501 & 550 & 1.9 \\
\hline [17] & 162 & 150 & 700 & 7.4 \\
\hline [19] & 828 & 922 & 400 & 11.4 \\
\hline [19] & 669 & 773 & 500 & 15.5 \\
\hline [19] & 272 & 408 & 600 & 49.8 \\
\hline [19] & 384 & 516 & 400 & 34.3 \\
\hline [11] & 1707 & 1717 & 400 & 0.5 \\
\hline [11] & 1652 & 1444 & 500 & 12.6 \\
\hline [11] & 1267 & 757 & 600 & 40.3 \\
\hline [11] & 1786 & 1608 & 400 & 9.9 \\
\hline [11] & 1728 & 1354 & 500 & 21.7 \\
\hline [11] & 1325 & 709 & 600 & 46.5 \\
\hline [11] & 2736 & 2208 & 400 & 19.3 \\
\hline [11] & 2496 & 1860 & 500 & 25.5 \\
\hline [11] & 1920 & 972 & 600 & 49.4 \\
\hline [12] & 4611 & 6200 & 500 & 34.5 \\
\hline [12] & 4974 & 6200 & 500 & 24.7 \\
\hline [12] & 7858 & 6200 & 500 & 21.1 \\
\hline [12] & 7858 & 6200 & 500 & 21.1 \\
\hline [11] & 1197 & 1302 & 400 & 8.7 \\
\hline [11] & 1092 & 1091 & 500 & 0.1 \\
\hline [11] & 840 & 575 & 600 & 31.5 \\
\hline [11] & 1368 & 1388 & 400 & 1.4 \\
\hline [11] & 1248 & 1163 & 500 & 6.8 \\
\hline [11] & 960 & 613 & 600 & 36.1 \\
\hline [11] & 1710 & 1601 & 400 & 6.4 \\
\hline [11] & 1560 & 1342 & 500 & 14.0 \\
\hline [11] & 1200 & 708 & 600 & 41.0 \\
\hline [13] & 800 & 697 & 450 & 12.9 \\
\hline [13] & 1500 & 1029 & 450 & 31.4 \\
\hline [13] & 240 & 275 & 650 & 14.6 \\
\hline [13] & 400 & 406 & 650 & 1.5 \\
\hline [13] & 750 & 383 & 450 & 48.9 \\
\hline [13] & 265 & 142 & 650 & 46.3 \\
\hline
\end{tabular}




\begin{tabular}{|c|c|c|c|c|}
\hline$[13]$ & 1400 & 696 & 450 & 50.3 \\
\hline$[13]$ & 360 & 257 & 650 & 28.5 \\
\hline$[20]$ & 637 & 601 & 450 & 5.6 \\
\hline$[20]$ & 237 & 238 & 650 & 0.3 \\
\hline$[20]$ & 498 & 314 & 450 & 37.0 \\
\hline$[20]$ & 195 & 124 & 650 & 36.6 \\
\hline$[21]$ & 637 & 556 & 450 & 12.6 \\
\hline$[21]$ & 230 & 220 & 650 & 4.3 \\
\hline$[21]$ & 484 & 313 & 450 & 35.3 \\
\hline$[21]$ & 201 & 123 & 650 & 38.6 \\
\hline$[22]$ & $265^{*}$ & $252^{*}$ & 415 & 4.8 \\
\hline$[22]$ & $110^{*}$ & $91^{*}$ & 615 & 17.2 \\
\hline$[22]$ & $263^{*}$ & $257^{*}$ & 415 & 2.2 \\
\hline$[22]$ & $112^{*}$ & $93^{*}$ & 615 & 17.1 \\
\hline$[22]$ & $156^{*}$ & $142^{*}$ & 415 & 9.0 \\
\hline$[22]$ & $68^{*}$ & $52^{*}$ & 615 & 24.4 \\
\hline$[22]$ & $451^{*}$ & $359^{*}$ & 415 & 20.5 \\
\hline$[22]$ & $186^{*}$ & $130^{*}$ & 615 & 30.1 \\
\hline
\end{tabular}

*These numbers refer to the ultimate bending moment $(\mathrm{kNm})$

\section{Local buckling of cold-formed structural elements at elevated temperatures}

The use of cold formed structural elements has become more common in the construction industry during the past decades due to the various advantages it offers, such as weight reduction of the structural system, ease of fabrication and construction etc. However, these thin-walled sections differ from hot-rolled sections in terms of failure modes (in addition to local and global buckling, distortional buckling is also possible). To investigate their structural behaviour when exposed to fire, researchers carried out experiments and numerical analyses of such members under elevated temperatures, with results and findings pertaining to the effect of local buckling on their failure being discussed in this section.

\subsection{Cold-formed structural elements experimental studies}

Various authors investigated the effect of local buckling on cold-formed steel columns subjected to fire. A thorough experimental work was carried out by Gunalan, Heva and Mahendran [40], who tested unlipped and lipped cold formed channel columns exposed to temperatures ranging from $100^{\circ} \mathrm{C}$ to $700^{\circ} \mathrm{C}$. The selected section thicknesses were such 
(slender web for lipped channels and thin flanges for unlipped ones) that the failure mode was local buckling and not distortional or flexural buckling. A total of 64 specimens were tested at elevated temperatures. The authors compared their experimental findings with finite element analysis results and reported good agreement. Moreover, they stated that the EN1993-1-2 [2] recommendations give too conservative predictions and suggested the use of the effective cross-sectional area at elevated temperatures instead [40]. Local flange buckling and web buckling can be observed for the two specimens shown in Fig. 8 . 
a)

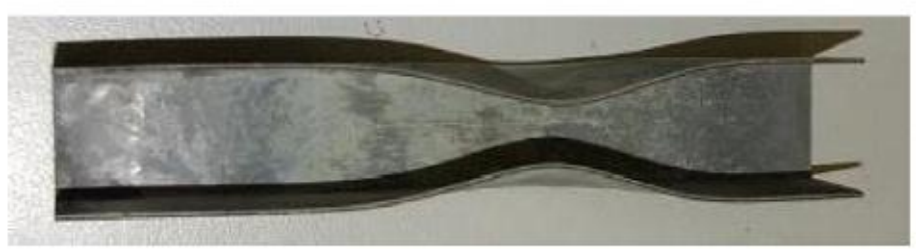

b)

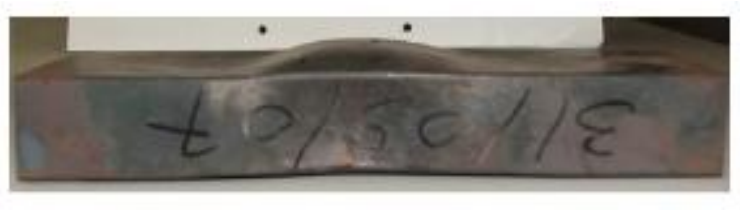

Figure 8: Typical local buckling failure a) of the flange b) of the web for cold formed steel specimens tested under fire exposure [40]

However, in other experimental work [41] regarding lipped channel and build-up open sections from two lipped channels, it was reported that local buckling had very limited presence in the failure mode of the heated columns. Contrary to the specimens prepared by Gunalan, Heva and Mahendran [40], which were designed to fail in local buckling due to their short length and cross-sectional geometry (high b/t ratios), the structural elements tested by Craveiro, Rodrigues and Laim [41] failed majorly as a result of global buckling due to their high slenderness and absence of lateral restraint. Another experimental program [42] included 52 steady state fire tests of lipped and unlipped channel columns exposed to fire. The authors reported that all unlipped sections failed due to local buckling. For the tested thin (1.2mm) lipped channels, local buckling was the predominant failure mode at temperatures lower than $400^{\circ} \mathrm{C}$, while distortional buckling was observed at higher temperatures. Contrary to this, the thicker sections failed mainly due to distortional buckling with limited local buckling and flexural bending. This is to be anticipated, because for very thin sections local buckling will be the governing failure mode due to the influence of a high $\mathrm{b} / \mathrm{t}$ ratio. Experimental results of built-up closed cold-formed columns at elevated temperatures [43] showed that the governing failure mode was global buckling, with local buckling appearing in some occasions (mostly around the column mid-height). This can be attributed, majorly, to the high slenderness of columns and their cross-sectional shape, which made them less 
susceptible to local buckling (stiffened elements with low width-to-thickness ratios $b / t<30$ for their webs and $b / t<6$ for their flanges approximately). On the other hand, Lee [44] tested specimens of short cold-formed columns made from either unlipped channel sections (30 tests) or lipped sections (90 tests) under elevated temperatures using the steady-state method and reported that local buckling was the only failure mode observed. Web local buckling, flange local buckling or both were observed based on the section type and geometry. Experimental results of lipped/unlipped short channel columns tested from various authors $[40,42,44]$ showed that these elements are susceptible to local buckling when subjected to fire, with their failure temperature depending, among other parameters, on the applied load ratio.

The effect of local buckling on cold-formed steel beams subjected to fire was investigated by Laím, Rodrigues, and Craveiro [45], who carried out more than 50 fire tests of beams with varying support conditions (simple supports, supports with rotational/axial restraint etc.). Six different cross-section types were tested (lipped channels, U channels, sigma profiles) and results showed that the beams failed primary due to flexural buckling accompanied with distortional buckling. Local buckling was only observed at the web of closed channels and lipped sections around the midspan and had a limited effect on the failure of the beams. The reason for this is the high slenderness of these beams (long beams with no lateral restraint). Moreover, some of the tested section types/shapes (e.g. sigma section) are less prone to local buckling due to their cross-sectional geometry (the bended shape of the web reduces the b/t ratio). Pictures of the failed beams were provided by the authors and are given in Fig. 9 . 


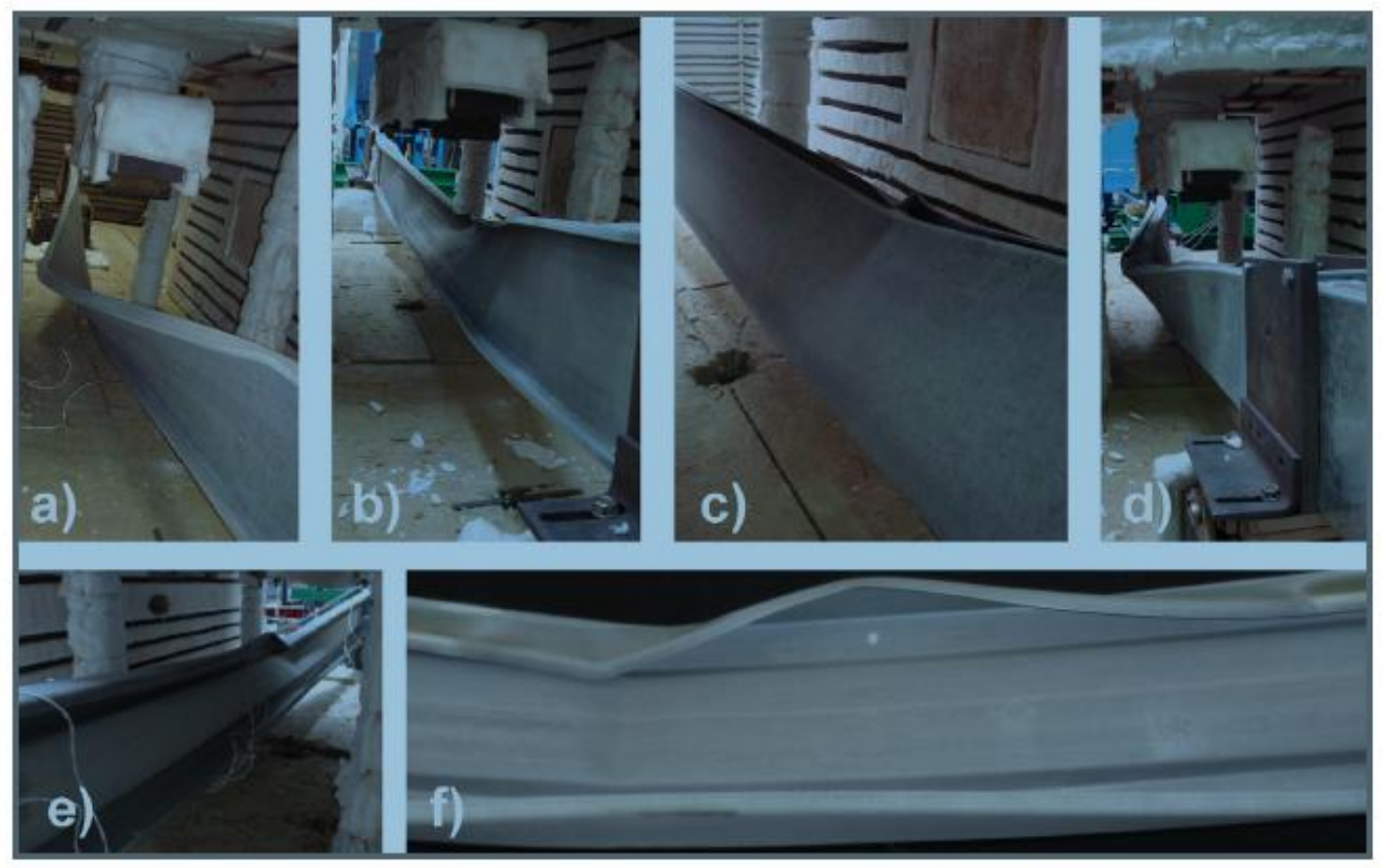

Figure 9: Failure of cold formed beams (a-f) involving local buckling after fire exposure [45]

\subsection{Cold-formed structural elements numerical and analytical studies}

Sivakumaran [46] analyzed cold-formed channel column stubs with a large web opening under elevated temperature effects via nonlinear finite element analysis and compared the results with those from his experimental program. The author faced simulation problems with the initiation of local buckling and the sensitivity of various analysis parameters affecting the results. In an attempt to simulate the behaviour of channel columns under elevated temperatures, various authors [40], [47] applied the FEM which incorporated local buckling effects and reported that comparisons with experimental results were satisfactory. Others [48], investigated, via the FEM, the effect of imperfections on the local buckling load of lipped cold-formed columns at elevated temperatures. The authors reported, after comparison with relevant experimental results, that increasing local imperfections reduces the compression stiffness of such elements. Shahbazian and Wang [49] also applied the FEM for axially loaded lipped channels in wall panels exposed to fire and, based on the results, proposed an analytical design method, which takes into account global, local and distortional buckling. 
The finite strip method (FSM), including local buckling modes, was applied by Cheng, Li and Kim [50] to describe the behaviour of partially protected cold-formed channel columns exposed to fire. An initial FE model was created to obtain the temperature distributions (uniform and non-uniform) used as input for the subsequent analyses. The same authors compared results of their analysis with finite element models and reported good accuracy. A picture of these models is given in (Fig. 10).

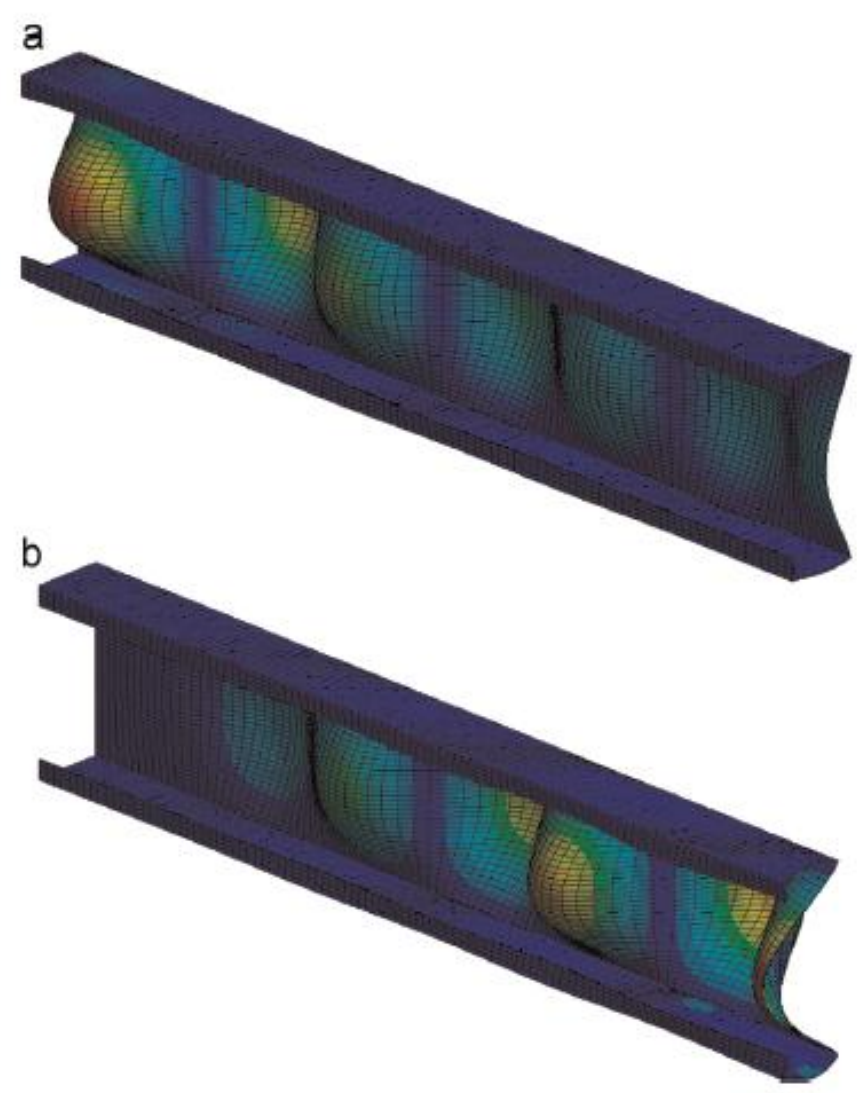

Figure 10: FEM simulations of cold-formed beams subjected to fire, with clear evidence of local buckling [50]

Others [51] compared the results of FE simulations (taking local buckling into account) of cold-formed slender channel columns subjected to fire with current design code methodologies (i.e. the effective width method and the direct strength method) and stated that the design provisions are conservative. Similarly, authors [52] compared calculations according to the Direct Strength Method (DSM) with an extensive database of FEM analysis results in an attempt to quantify the effect of local buckling for channel columns under 
elevated temperatures. They concluded that the DSM is applicable, but suggested modifications by introducing new buckling equations when the temperature is not uniform within the cross-section. In another FEM parametric study, Feng, Wang and Davies [53] investigated the failure modes of cold-formed tubular columns with different slenderness parameters exposed to fire and reported local buckling in many occasions, while stressing the effect of initial geometric imperfections. Moreover, Lee [44] used both the FEM and the FSM to model the results of his experiments and reported good agreement between test results and simulations. Cheng, Li and Kim [54] investigated numerically the effect of fire exposure from one side on the structural behaviour of cold channel beams partially protected with plasterboard. Initially, they carried out 2D finite element heat transfer analyses to obtain the temperature evolution in the beam. Afterwards, they applied the FSM to obtain the critical moment depending on the temperature of the section and the length considered. They reported that, for the investigated sections, there is a distinct region in the slenderness axis (for short beams) where the failure is expected to occur due to local buckling [54].

\subsection{Discussion of the literature}

Table 6 summarizes all the above collected data (experimental and numerical) and provides reference of their sources. Table 7 provides additional information related to the fire testing conditions of cold formed steel members as reported in the literature. A quick observation shows that the majority of the authors tested cold-formed channel columns ( 268 experiments from four sources). On the contrary, only 50 fire tests involved beams (reported only in one source). Similarly, numerical investigations focus mainly on columns (eight sources) with limited reference to beams (only one source).

It can also be noted that essentially columns made from channel sections have been tested; the effect of local buckling for structural elements made from other section types has not 
been thoroughly investigated. The absence of data pertaining to beams is especially remarkable. The FEM and was most commonly used to simulate the effect of local buckling at elevated temperatures, with the authors reporting good agreement in comparisons they made with experimental results. All authors successfully take into account the various factors that influence the FEM results such as the mesh, the initial imperfections, stress-strain relationship etc. On the contrary, the analytical expressions proposed have to be compared against a larger sample of test specimens or simulations, including other section types before they can be put into practice. The FSM was also successfully implemented on a buckling analysis of such members under elevated temperatures. It has an advantage over the FEM in terms of computational effort and is a very efficient method for calculations pertaining to members under pure compression (uniformly heated members). However, when a temperature gradient exists in the cross-section, the method has to be modified to take into account the varying material properties and pre-buckling stress distributions, making it harder to apply.

Table 6: Experimental data and numerical simulations of cold-formed members exposed to fire

\begin{tabular}{|c|c|c|c|c|c|}
\hline Source & $\begin{array}{c}\text { Member } \\
\text { Type }\end{array}$ & Cross-section & Experiments & $\begin{array}{c}\text { No. of } \\
\text { specimens with } \\
\text { Local Buckling } \\
\text { Failure }\end{array}$ & $\begin{array}{c}\text { Analysis } \\
\text { Method }\end{array}$ \\
\hline$[40]$ & Columns & Channels & 64 & 64 & FEM \\
\hline$[42]$ & Columns & Channels & 52 & 36 & - \\
\hline$[43]$ & Columns & Closed Built-up & 48 & Not specified & - \\
\hline$[44]$ & Columns & Channels & 120 & 120 & FEM+FSM \\
\hline$[45]$ & Beams & Various & 50 & Not specified & - \\
\hline$[46],[47],[48]$ & Columns & Channels & - & - & FEM \\
\hline$[49]$ & Columns & Channels & - & - & FEM+Equations \\
\hline$[50]$ & Columns & Channels & - & - & FEM+FSM \\
\hline$[51],[52]$ & Columns & Channels & - & - & FEM+Equations \\
\hline$[53]$ & Columns & Tubes & - & - & FEM \\
\hline$[54]$ & Beams & Channels & - & - & FSM \\
\hline
\end{tabular}


Table 7: Information regarding the fire tests of cold-formed members collected from the literature

\begin{tabular}{|c|c|c|c|c|c|}
\hline Source & $\begin{array}{c}\text { Member } \\
\text { Type }\end{array}$ & Cross-section & $\begin{array}{c}\text { Heating } \\
\text { method }\end{array}$ & $\begin{array}{c}\text { Loading } \\
\text { Condition }\end{array}$ & $\begin{array}{c}\text { Boundary } \\
\text { Conditions }\end{array}$ \\
\hline$[40]$ & Columns & Channels & Steady-state & Axial Load & $\begin{array}{c}\text { No axial } \\
\text { restraint, } \\
\text { rotational } \\
\text { restraint at ends }\end{array}$ \\
\hline$[42]$ & Columns & Channels & Steady-state & Axial Load & Fixed ends \\
\hline$[43]$ & Columns & Closed Built-up & $\begin{array}{c}\text { Transient, } \\
\text { ISO834 curve }\end{array}$ & Axial Load & $\begin{array}{c}\text { Pinned or semi- } \\
\text { rigid ends }\end{array}$ \\
\hline$[44]$ & Columns & Channels & Steady-state & Axial Load & Fixed ends \\
\hline$[45]$ & Beams & Various & $\begin{array}{c}\text { Transient, } \\
\text { ISO834 curve }\end{array}$ & $\begin{array}{c}\text { Bending, two } \\
\text { point loads }\end{array}$ & $\begin{array}{c}\text { Ends with axial } \\
\text { \& rotational } \\
\text { restraint }\end{array}$ \\
\hline
\end{tabular}

In the figures presented below, the load ratio of cold-formed channel columns tested under steady-state thermal exposure is plotted against the reported failure temperature for specimens that experienced distinctly either local web buckling (Fig. 11) or local flange buckling (Fig. 12).

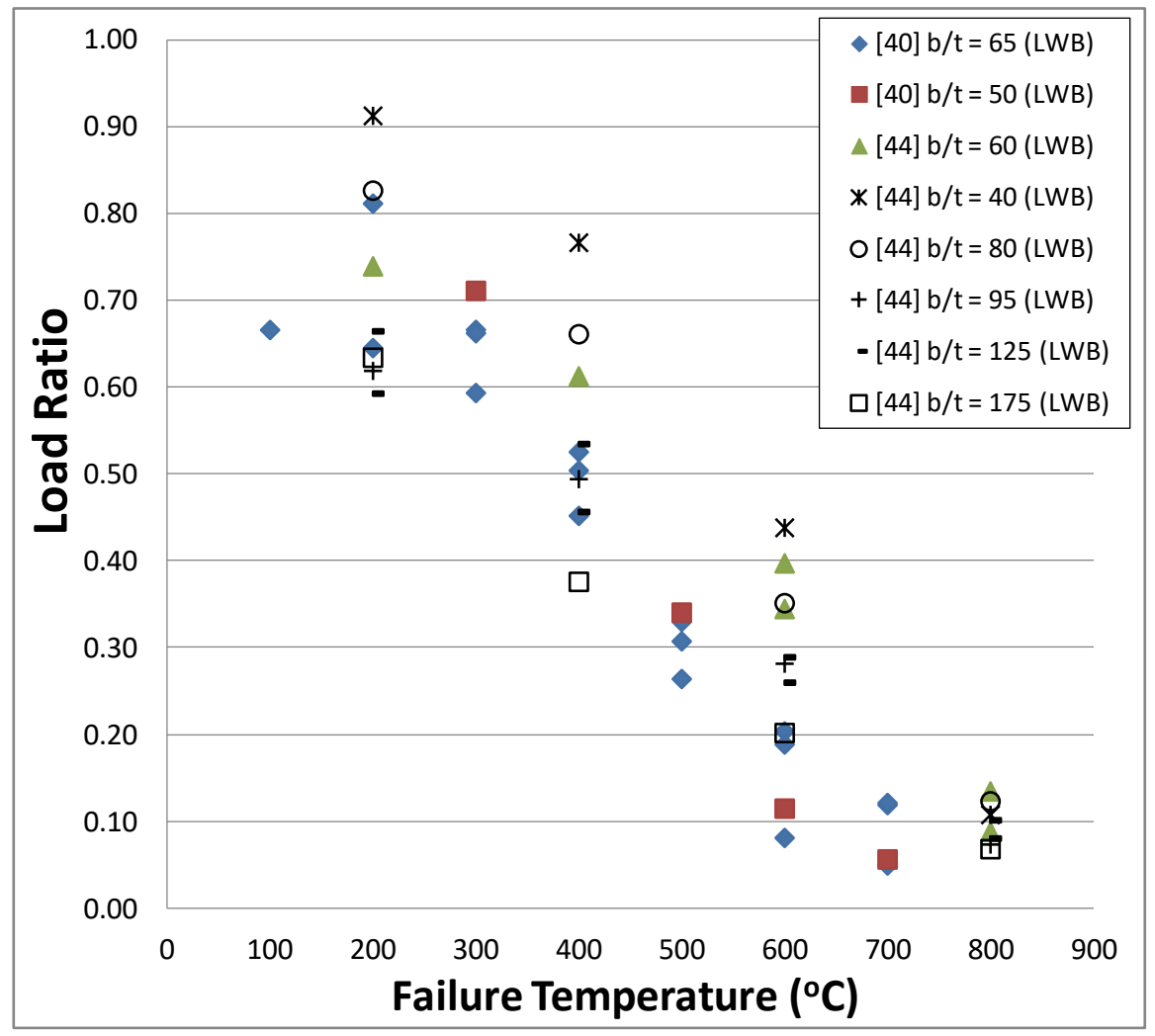


Figure 11: Plot of the load ratio versus the failure temperature for stocky cold-formed columns experiencing local web buckling under elevated temperatures (experimental data collected from the literature)

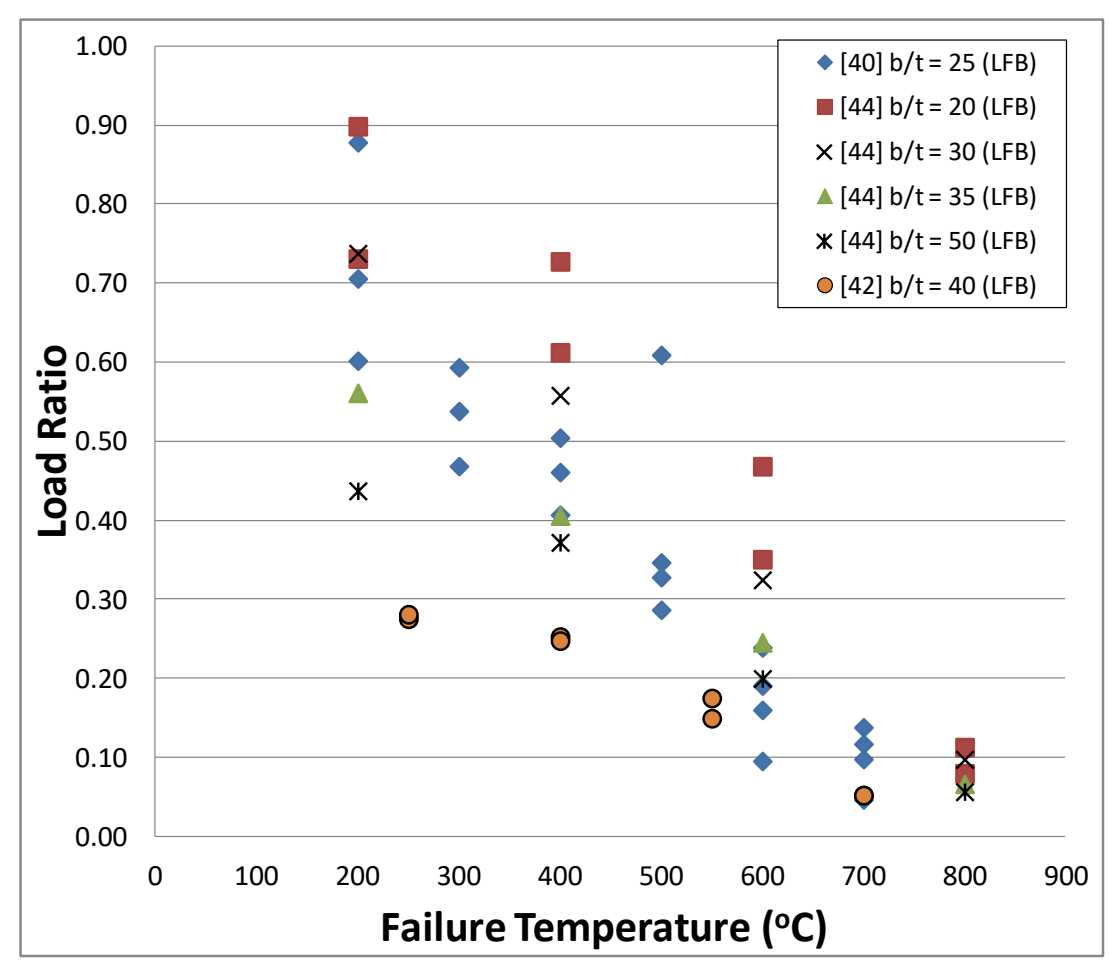

Figure 12: Plot of the load ratio versus the failure temperature for stocky cold-formed columns experiencing local flange buckling under elevated temperatures (experimental data collected from the literature)

The data shown refer to specimens in which local buckling was the only failure mode (not combined with other failure modes, i.e. distortional or global buckling) and were collected from three sources ([40], [42], [44]). The load ratio is defined as for hot-formed sections (for short and stocky columns). The plate slenderness ratio b/t is also marked in these figures. Despite scatter in the data, the two plots show the anticipated failure at lower load ratios with temperature increase for columns that experience local buckling. Observation of the plots shows an almost linear decrease of the sustained load ratio for the temperature region between $200^{\circ} \mathrm{C}$ and $600^{\circ} \mathrm{C}$. Afterwards, and until $800^{\circ} \mathrm{C}$, its reduction occurs in a less rapid way. This clearly shows the effect of material deterioration with temperature rise on the capability of the columns to sustain the applied loading. There is also the trend, in general, that greater $b / t$ ratios result to a lower load ratio for specimens failing at approximately the 
same temperature. The plotted results also show that short/stocky columns exposed to fire are expected to experience local flange buckling (LFB) when the b/t ratio of the flange exceeds 20 and local web buckling (LWB) when the b/t ratio of the web exceeds 40 .

\section{Discussion of other considerations regarding local buckling of steel members exposed to fire}

According to accumulated literature results, the slenderness of steel members is a major factor in determining their failure mode at elevated temperatures. Short, stocky elements typically have a slenderness ratio less than 40 , while in long, slender elements this value is greater than 120. The tested stocky columns all exhibited local buckling as their failure mode, while longer, more slender columns displayed global buckling accompanied by limited local buckling. However, due to the absence of the data for columns with medium slenderness ( i.e. with a slenderness ratio ranging, indicatively, from 40 to 120), a distinct region or limit for this transition in the failure mode cannot be established. Regarding beams, the lateral restraint was the determining factor of the failure mode, with all authors who conducted relevant work $[20,21,22]$ agreeing to this. Similarly, experimental results showed that stocky, cold-formed elements fail in local buckling when heated, but a threshold slenderness limit beyond which distortional / global buckling will occur instead, cannot be clearly determined.

Initial imperfections were measured to be small (less than L/1000) in most experiments and did not have a profound effect on the initiation of local buckling according to the authors. Imperfections with greater magnitude were introduced in the experimental work of two sources [21,22] with no comments being made regarding their effect on local buckling. Their influence at determining the position of local buckling was discussed by only one author [15]. On the other hand, geometric imperfections were modelled in FE simulations with authors reporting their adverse effect on the capacity of the member due to local buckling $[26,27,35]$. Despite these observations, more quantitative experimental work is necessary to establish the 
effect of initial geometric imperfections on local buckling failure of heated steel elements. Their role is much more profound on cold-formed elements, in which they can even determine the failure mode according to the conclusions of some authors who investigated this experimentally [41, 42] and numerically [47]. Others [48] stated that local imperfections reduce the stiffness of channel cold-formed columns and should not be omitted when calculating the ultimate strength of such members at elevated temperatures.

The accumulated experimental results show that the temperature distribution for the majority of the tested elements is approximately uniform, because most tests involved steady state heating conditions and similar thermal boundary conditions from all fire exposure sides. Only in one source [20], the tested steel beams exhibited a temperature gradient between their lower and upper flanges ranging approximately from $20^{\circ} \mathrm{C}$ to $120^{\circ} \mathrm{C}$ (not severe gradient). Even though it can be expected that a severe temperature gradient would adversely affect the resistance to local buckling, because of the additional stresses induced by it, this statement cannot be justified based on the existing literature. On the contrary, numerical analysis of cold-formed sections with a temperature gradient $[50,54]$ showed that it has a negligible effect on local buckling. However, more work is required to investigate its effect, which could be crucial for certain elements types that are expected to experience thermal bowing (e.g. beams supporting a slab, with or without composite action).

Fire protection will certainly delay the appearance of local buckling, by preventing the rapid increase of temperature in the cross-section of the steel structural member. Its existence, however, does not affect the mechanics of the phenomenon at elevated temperatures and, for this reason, researchers selected to test unprotected elements. Thermal insulation will only influence it by means of altering the temperature distribution of the cross-section (introduction of temperature gradient) when applied partially (e.g. from only one side of the element), in which case it should be investigated as explained in the previous section. This is 
the reason it was introduced in the numerical analysis of cold-formed sections carried out by authors $[50,54]$.

In common practice, the Eurocode is typically used when designing against local buckling of steel members exposed to fire. Its applicability has also been discussed by several authors conducting relevant research. As reported [13], test results from column stubs show that the capacity calculated by the specific code is greater than the experimental values by up to $30 \%$. Contrary to this, other experiments [17] or numerical simulations [21] show that the specific code produces more conservative when calculating the failure load of such elements experiencing local buckling under elevated temperature effects. A comparison of the calculated critical loads according to the Eurocode, at the reported failure temperature, with the measured experimental failure loads for columns ([11],[12],[14],[17],[19]), shows that the code is conservative by approximately $5 \%$ to $20 \%$, irrespectively of the column type (welded or hot-rolled) or the cross-section (H-shape or box section). In one source [32], the authors stated that the results obtained from the Eurocode were either very conservative or unsafe compared with those of their numerical simulations. A comparison with numerical modelling from other sources also shows inconsistency, with Eurocode calculations either exceeding the simulation results typically by 10 to $15 \%$ or being conservative by 5 to $20 \%$. The elevated temperature resistance of the beams from one source [34], calculated according to the Eurocode, also displayed similar inconsistencies when compared with results from numerical simulations (i.e. either over predicted or underestimated the values from the simulations). Based on the above observations and the contradictory statements by the different authors, it can be concluded that the methodology of this code should be improved in terms of accuracy, by comparison with a wider range of relevant, existing and future, experimental results. Moreover, its practicality could be improved by simplifying some of the equations or removing the cross-section classification step in the design process. 


\section{Conclusions and knowledge gaps}

Based on the collected data, the numerical simulations encountered in the literature and the previous discussions, several conclusions can be drawn. More specifically, local buckling in hot-formed steel columns exposed to fire typically occurs for temperatures ranging from $400^{\circ} \mathrm{C}$ to $700^{\circ} \mathrm{C}$ when the load ratio varies between 0.90 and 0.10 . Higher plate slenderness ratios $b / t$ reduce the failure temperature of the heated member for a given load ratio. Furthermore, stocky columns subjected to fire do not exhibit local buckling if heated up to $600^{\circ} \mathrm{C}$, if their load ratio is less than 0.55 and the $\mathrm{b} / \mathrm{t}$ ratio does not exceed $0.41 *\left(\mathrm{E} / \mathrm{f}_{\mathrm{y}}\right)^{1 / 2}$ (unstiffened elements) or $1.14 *\left(\mathrm{E} / \mathrm{f}_{\mathrm{y}}\right)^{1 / 2}$ (stiffened elements). It can also be stated that the sustained load ratio for hot-formed beams susceptible to local buckling under fire exposure can increase by $45 \%$ (when the temperature is between $400^{\circ} \mathrm{C}-450^{\circ} \mathrm{C}$ ) or even by $80 \%$ (for the $600^{\circ} \mathrm{C}-650^{\circ} \mathrm{C}$ temperature region) when the flange $\mathrm{b} / \mathrm{t}$ ratio is less or equal than 8 .

Additionally, the critical temperatures proposed in the literature for class 4 cross-sections compare well with experimental data collected in this paper and can provide a good estimate (generally on the safe side) for the failure temperature of steel members susceptible to local buckling.

In general, the FEM and FSM are efficient in simulating local buckling of steel elements exposed to fire. Analytical expressions proposed in the literature for calculating the buckling of steel plates under elevated temperatures can provide a rough estimate (typically within $25 \%$ ) for the failure load of heated steel members prone to local buckling.

Moreover, the effect of local buckling in cold-formed structural elements under elevated temperatures has been mostly investigated for channel columns, with some reference being made to beams of various cross-sections. For stocky cold-formed columns with channel 
sections exposed to fire, local flange buckling is expected to occur for plate slenderness ratios $b / t>20$ and local web buckling for $b / t>40$.

Despite being the most common code of practice, the Eurocode is not conservative at all occasions according to the accumulated results and can, in certain cases be unsafe when calculating the failure load of heated steel sections prone to local buckling. Designers should use it with caution and improvements related to its accuracy and simplicity are deemed necessary.

Future research on the subject of local buckling of steel members under elevated temperatures should include a wider experimental database. The effect of local buckling has not been experimentally established, for slender columns or members subjected to compression and bending concurrently (beam-column elements). Tests involving beams are also few and limited to I-shaped sections. More experiments of such elements including other section types (e.g. box sections) should be carried out. The application of a non-uniform temperature distribution within the cross-section of the element on local buckling should be investigated experimentally and numerically. For example, a comparison of pairs of identical beams with the same loading/support conditions in which one beam will experience thermal gradient will certainly be of interest and is expected to provide insight pertaining to this specific issue. The effect of initial imperfections should also be established in future experimental work, by means of comparing identical elements with different magnitudes of imperfections. Moreover, the prevention of the phenomenon by strengthening the heated elements at regions where local buckling is expected to occur (e.g. by adding stiffeners) needs to be researched in the future, as it is completely absent from the current work and contemporary design practices. Regarding cold-formed steel elements, the lack of test results pertaining to beams is noteworthy. More experimental work in this direction, including a larger variety of cross-sections, is necessary in the future. Furthermore, the existing analytical 
expressions describing the local buckling of cold-formed elements require validation against a larger sample of simulations or experimental results.

\section{Acknowledgments}

This research was supported by the University of Liege and the EU in the context of the FP7PEOPLE-COFUND-BeIPD project.

\section{References}

[1] European Committee for Standardisation (ECS). EN 1993-1-1, Eurocode 3: Design of steel structures - Part 1-1: General rules and rules for buildings. Brussels, Belgium; 2005.

[2] European Committee for Standardization (ECS). EN 1993-1-2, Eurocode 3: Design of steel structures. Part 1.2: General rules — Structural fire design. Brussels, Belgium; 2005.

[3] American Institute of Steel Construction (AISC). Standard ANSI/AISC360-05, Specifications for Structural Steel Buildings. Chicago,IL, USA; 2005.

[4] Quiel, S., Garlock, M. Calculating the buckling strength of steel plates exposed to fire. Thin-Walled Structures 2010;48:684-695.

[5] European Committee for Standardization (ECS). EN 1993-1-3, Eurocode 3: Design of steel structures. Part 1.3: General rules-Supplementary rules for cold-formed members and sheeting, Brussels, Belgium, 2006.

[6] American Iron and Steel Institute (AISI). Specifications for the cold-formed steel structural members. Cold-formed Steel Design Manual. Washington (DC), USA; 2007.

[7] British Standards Institution (BSI). British Standard 5950: Structural use of steelwork in buildings. Part 5: Code of practice for design of cold-formed thin gauge sections. London,UK; 1998.

[8] Standards Australia (SA). Cold-formed steel structures, AS/NZS 4600. Sydney, Australia; 2005 .

[9] American Iron and Steel Institute (AISI). Supplement to the North American Specification for design of cold-formed steel structural members. Washington (DC), USA; 2004.

[10] British Standards Institution (BSI). British Standard 5950: Structural use of steelwork in Buildings. Part 8: Code of practice for fire resistant design. London, UK; 2005. 
[11] Yang, K.C., Chen, S.J., Lin, C.C., Lee, H.H. Experimental study on local buckling of fire-resisting steel columns under fire load. Journal of Constructional Steel Research 2005;61:553-565.

[12] Yang, K.C., Yang, F.C. Fire performance of restrained welded steel box columns. Journal of Constructional Steel Research 2015;107:173-181.

[13] Wang,W., Kodur,V., Yang,X., Li,G. Experimental study on local buckling of axially compressed steel stub columns at elevated temperatures. Thin-Walled Structures 2014;82:3345 .

[14] Franssen, J.M., Fohn, T. FIDESC4: Fire behaviour of steel members with class 4 cross sections under axial compression and axial compression with eccentricity. Report of the experimental tests performed at the University of Liège; 2013.

[15] Franssen, J.M., Zhao, B. Gernay, T. Experimental tests and numerical modelling on slender steel columns at high temperatures. Journal of Structural Fire Engineering (under press).

[16] Franssen, J.M., Zhao, B., Gernay, T. Experimental tests and numerical modelling on eight slender steel columns under increasing temperatures. 8th International Conference on Structures in Fire. Shanghai, China, June 11-13, 2014.

[17] Theofanous, M., Propsert, T., Knobloch, M., Gardner, L. The continuous strength method for steel cross-section design at elevated temperatures. Thin-Walled Structures 2016;98:94-102.

[18] Knobloch, M., Somaini, D., Pauli, J., Fontana, M. Stability of steel columns subjected to fire. Stability and ductility of steel structures. Rio de Janeiro, Brazil, September 8 - 10, 2010.

[19] Hirashima,T., Hideki, U. Load-bearing Capacity of H-shaped Steel Columns under Local Buckling at Elevated Temperature. Fire safety science-proceedings of the 8th international symposium, 211-222.

[20] Prachar, M., Hricak, J., Jandera, M., Wald, F., Zhao, B. Experiments of Class 4 open section beams at elevated temperature. Thin-Walled Structures 2016;98(1): 2-18.

[21] Franssen, J.M., Morente, F., Vila Real, P., Wald, F., Sanzel, A., Zhao, B. Fire Design of Steel Members with Welded or Hot-rolled Class 4 Cross-sections Technical Report. No: Report n.6. 2015.

[22] Dharma, R.B., Tan, K.H. Rotational capacity of steel I-beams under fire conditions-Part I: Experimental study. Engineering Structures 2007; 29(9):2391-2402.

[23] Couto, C., Vila Real, P., Lopes, N., Zhao, B. Resistance of steel cross-sections with local buckling at elevated temperatures. Journal of Constructional Steel Research 2015;109:101114. 
[24] Heidarpour, A., Bradford, M.A. Local buckling and slenderness limits for steel webs under combined bending, compression and shear at elevated temperatures. Thin-Walled Structures 2008; 46:128-146.

[25] Ragheb, W.F. Estimating the local buckling capacity of structural steel I-section columns at elevated temperatures. Thin-Walled Structures 2016;107:18-27.

[26] Seif, M., McAllister, T. Stability of wide flange structural steel columns at elevated temperatures. Journal of Constructional Steel Research 2013;84:17-26.

[27] Wang, W., Ohmiya, Y., Ma, G. Fire resistance study of axially loaded high strength steel columns. The 9th Asia-Oceania Symposium on Fire Science and Technology. Procedia Engineering 2013; 62: $690-701$.

[28] Knobloch, M. Local Buckling Behavior of Steel Sections Subjected to Fire. Fire safety science-proceedings of the 9th international symposium, 1239-1125.

[29] Franssen, J.M., Cowez, B. and Gernay, T. Effective stress method to be used in beam finite elements to take local instabilities into account. Fire Safety Science 2014;11:544-557.

[30] Agarwal, A., Varma, A.H., Cedeno, G. Steel columns under fire loading: stability behaviour and design. SSRC Annual Stability Conference. Phoenix, AZ, U.S.A., 2011.

[31] Selamet, S., Garlock, M.E. Local buckling study of flanges and webs in i-shapes at elevated temperatures. Proceedings of the 2010 Structures Congress, Orlando, Florida, U.S.A. May 12-15, 2010.

[32] Couto, C., Vila Real, P., Lopes, N., Zhao, B. A new design method to take into account the local buckling of steel cross-sections at elevated temperatures. 8th International Conference on Structures in Fire. Shanghai, China, June 11-13, 2014.

[33] Naser, M.Z., Kodur. V.K.R. Factors governing onset of local instabilities in fire exposed steel beams. Thin-Walled Structures 2016;98:48-57.

[34] Couto, C., Vila Real, P., Lopes, N., Zhao, B. Numerical investigation of the lateraltorsional buckling of beams with slender cross sections for the case of fire. Engineering Structures 2016;106:410-421.

[35] Dharma, R.B., Tan, K.H. Rotational capacity of steel I-beams under fire conditions-Part II: Numerical simulations. Engineering Structures 2007; 29(9):2403-2418.

[36] Couto, C., Vila Real, P., Lopes, N., Zhao,B. Local buckling in laterally restrained steel beam-columns in case of fire. Journal of Constructional Steel Research 2016;122:543-556.

[37] Maia,E., Couto,C., Vila Real,P., Lopes,N. Critical temperatures of class 4 cross-sections. Journal of Constructional Steel Research 2016;121: 370-382.

[38] Knobloch, M., Fontana, M. Strain-based approach to local buckling of steel sections subjected to fire. Journal of Constructional Steel Research 2006; 62: 44-67. 
[39] Couto, C., Vila Real, P., Lopes, N., Zhao,B. Effective width method to account for the local buckling of steel thin plates at elevated temperatures. Thin-Walled Structures 2014; 84:134-149.

[40] Gunalan, S., Heva, Y.B., Mahendran, M. Local buckling studies of cold-formed steel compression members at elevated temperatures. Journal of Constructional Steel Research 2015;108:31-45.

[41] Craveiro, H.D., Rodrigues, J.P.C., Laím, L. Cold-formed steel columns made with open cross-sections subjected to fire. Thin-Walled Structures 2014; 85:1-14.

[42] Feng, M., Wang, Y.C., Davies., J.M. Structural behaviour of cold-formed thin-walled short steel channel columns at elevated temperatures. Part 1: experiments. Thin-Walled Structures 2003; 41:543-570.

[43] Craveiro, H.D., Rodrigues, J.P.C., Laím, L. Experimental analysis of built-up closed cold-formed steel columns with restrained thermal elongation under fire conditions. ThinWalled Structures 2016; 107:564-579.

[44] Lee, J.H. Local buckling behaviour and design of cold-formed steel compression members at elevated temperatures. Phd Thesis, Queensland University; 2004.

[45] Laím, L., Rodrigues, J.P.C., Craveiro, H.D. Flexural behaviour of axially and rotationally restrained cold-formed Steel beams subjected to fire. Thin-Walled Structures 2016;98:39-47.

[46] Sivakumaran K. S. Analysis for local buckling capacity of cold-formed steel sections with web opening. Computers and structures 1987; 26(1):275-282.

[47] Feng, M., Wang, Y.C., Davies., J.M. Structural behaviour of cold-formed thin-walled short steel channel columns at elevated temperatures. Part 2: Design calculations and numerical analysis. Thin-Walled Structures 2003; 41:571-594.

[48] Kaitila, O. Imperfection sensitivity analysis of lipped channel columns at high temperatures. Journal of Constructional Steel Research 2002; 58:333-351.

[49] Shahbazian, A., Wang, Y.C. A fire resistance design method for thin-walled steel studs in wall panel constructions exposed to parametric fires. Thin-Walled Structures 2014;77:6776.

[50] Cheng, S., Li, L., Kim, B. Buckling analysis of partially protected cold-formed steel channel- section columns at elevated temperatures. Fire Safety Journal 2015;72:7-15.

[51] Chen, J., Young, B. Cold-formed steel lipped channel columns at elevated temperatures. Engineering Structures 2007;29:2445-2456. 
[52] Shahbazian, A., Wang, Y.C. Application of the Direct Strength Method to local buckling resistance of thin-walled steel members with non-uniform elevated temperatures under axial compression. Thin-Walled Structures 2011;49:1573-1583.

[53] Feng, M., Wang, Y.C., Davies., J.M. A numerical imperfection sensitivity study of coldformed thin-walled tubular steel columns at uniform elevated temperatures. Thin-Walled Structures 2004; 42:533-555.

[54] Cheng, S., Li, L., Kim, B. Buckling analysis of cold-formed steel channel-section beams at elevated temperatures. Journal of Constructional Steel Research 2015;104:74-80. 